\title{
TLR Agonist Conjugation: A Chemical Perspective
}

\author{
Bob J. Ignacio ${ }^{\dagger, \pi}$, Tyler J. Albin ${ }^{\ddagger}$, , Aaron P. Esser-Kahn ${ }^{\ddagger, \S, *}$, Martijn Verdoes ${ }^{\dagger, *}$ \\ ${ }^{\dagger}$ Department of Tumor Immunology, Radboud Institute for Molecular Life Sciences, Radboud University Nijmegen Medical \\ Center, Nijmegen, The Netherlands \\ Department of Chemistry, University of California, Irvine, Irvine, California 92697, United States \\ $\S$ Institute for Molecular Engineering, University of Chicago, Chicago, Illinois 60637, United States \\ " These authors contributed equally to this work. \\ * Email: aesserkahn@uchicago.edu; Martijn.Verdoes@Radboudumc.nl \\ * Phone: +1(248) 376 7611; +31 (0)243617600
}

\begin{abstract}
Toll-like receptors (TLRs) are vital elements of the mammalian immune system that function by recognizing pathogenassociated molecular patterns (PAMPs), bridging innate and adaptive immunity. They have become a prominent therapeutic target for the treatment of infectious diseases, cancer, and allergies, with many TLR agonists currently in clinical trials or approved as immunostimulants. Numerous studies have shown that conjugation of TLR agonists to other molecules can beneficially influence their potency, toxicity, pharmacokinetics, or function. The functional properties of TLR agonist conjugates, however, are highly dependent on the ligation strategy employed. Here, we review the chemical structural requirements for effective functional TLR agonist conjugation. In addition, we provide similar analysis for those that have yet to be conjugated. Moreover, we discuss applications of covalent TLR agonist conjugation and their implications for clinical use.
\end{abstract}

\section{- Introduction}

The immune system is vital in protecting the body against infectious disease and cancers. Toll-like receptor (TLR) activation is the first step in stimulating the immune system to respond to disease. ${ }^{1}$ As a consequence, TLRs are the target of several therapeutics, including vaccines ${ }^{2}$, cancer immunotherapies $^{3}$, and autoimmune disease treatments. ${ }^{4,5}$ Activators of TLR signaling, TLR agonists, are powerful immunostimulants due to their ability to drive innate and acquired immunity and are therefore sought after as adjuvants in vaccines. ${ }^{6}$ However, because they elicit strong immune reactions, administration of TLR agonists can have toxic sideeffects in vivo. ${ }^{7-9}$

To mitigate these adverse effects, TLR agonists can be covalently conjugated to an antigen. This ensures simultaneous delivery of antigen and adjuvant to the same antigen presenting cell, which directs the response toward the antigen, thereby lowering the required dose for an effective immune response. $^{10,11}$ These self-adjuvanting vaccines induce stronger humoral and cellular immune responses and are less toxic than vaccines comprised of co-administered antigen and adjuvant. ${ }^{10}$ TLR agonists have also been conjugated to polymers ${ }^{12-14}$, solid particles $^{15-17}$, or phospholipids ${ }^{18-20}$ to beneficially influence the compound's drug properties.

The benefits of TLR agonist conjugation can only be achieved if the conjugation does not perturb the interaction between the agonist and receptor. Therefore, effective strategies are required that facilitate TLR agonist conjugation with retention, or improved, TLR agonist potency. Here, we provide a review of the chemical requirements for successful TLR agonist conjugation strategies that have been employed, provide suggestions for alternative ligation strategies for existing TLR agonists, and insight for agonists that have yet to be conjugated.

\section{- TLRs - Nomenclature and Function}

Toll-like receptors are a class of transmembrane pattern recognition receptors (PRRs). Their role is to recognize conserved molecular components of pathogens called "pathogen-associated molecular patterns" (PAMPs) as well as cellular damage-associated molecular patterns (DAMPs). ${ }^{21}$ The receptors are predominantly expressed in immune cells and show distinct expression patterns across different cell types. ${ }^{22}$

The human TLR family comprises 10 functional TLRs that are expressed both on the cell surface (TLR1, 2, 4, 5 and 6) and intracellularly in endosomal compartments (TLR 3, 4, 7, 8 and $9) .^{23,24}$ The cellular localization of TLRs reflects the origin of the ligand it is responsible for detecting (Fig. 1). TLRs found at the cell surface respond to extracellular components of pathogens, including lipoproteins (TLR1, 2 and 6), lipopolysaccharides (TLR4), and bacterial flagellin (TLR5). Endosomal TLRs recognize components from the intracellular compartments of pathogens, such as double-stranded RNA (dsRNA, TLR3), single-stranded RNA (ssRNA, TLR7 and 8) and unmethylated cytosine-phosphate-guanine (CpG) DNA (TLR9). ${ }^{25}$ Although the role and natural ligand for human TLR10 is not yet fully understood, it is thought to be a negative regulator of TLR signaling. ${ }^{26-28}$ Binding of ligands to TLRs induces homo- or hetero-dimerization of TLR receptors and subsequent downstream signaling through two distinct pathways, the MyD88-dependent (TLRs 1, 2 and 4-9) and 


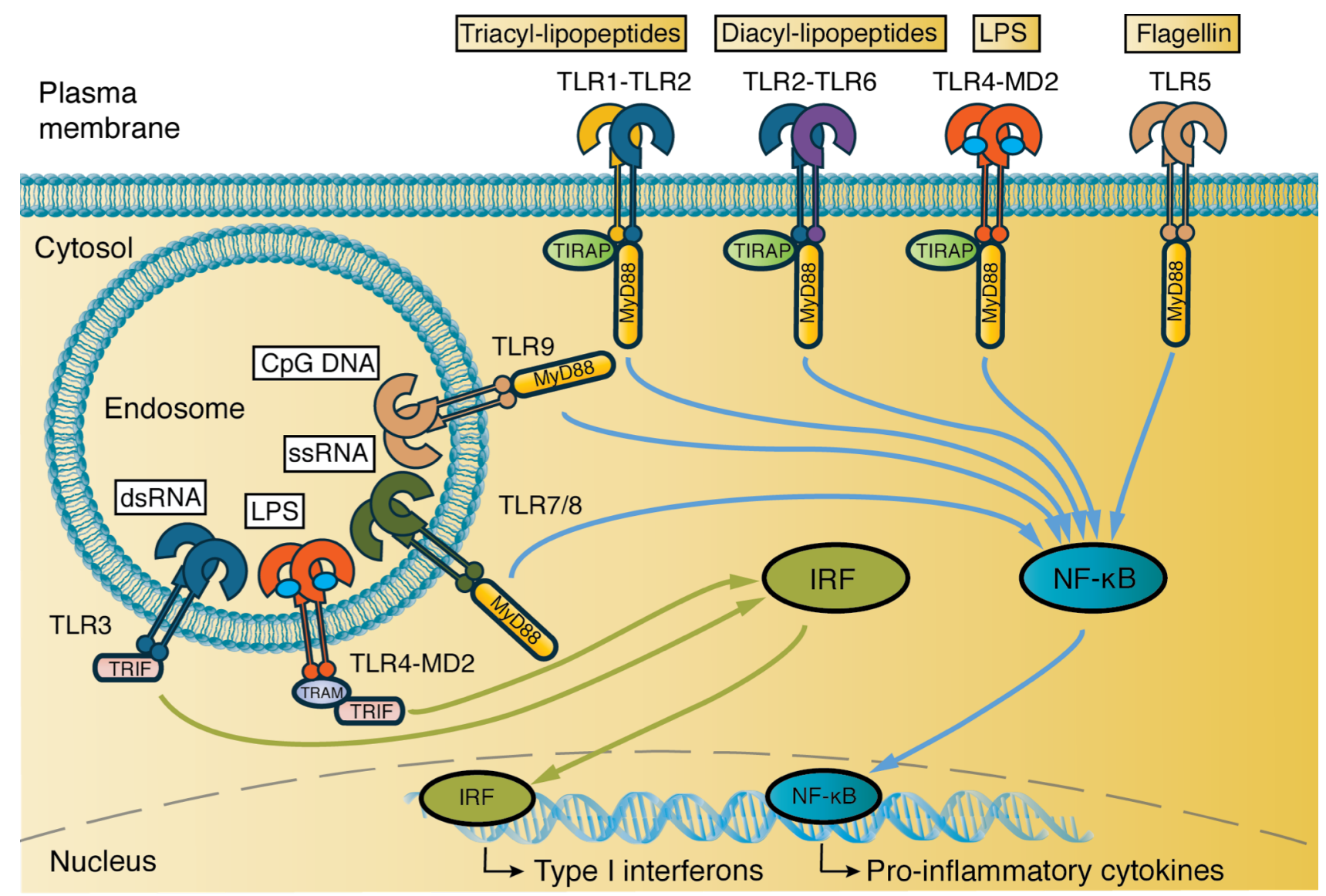

Figure 1. Cellular location of TLRs, their ligands, and signal transduction pathways. TLRs 1, 2, 6, 4 and 5 are located on the plasma membrane and signal, together with endosomal TLRs 7, 8, and 9, in a MyD88-dependent manner. The MyD88 pathway leads to NF- $\mathrm{B}$ translocation to the nucleus and, ultimately, production of inflammatory cytokines. Activated TLR4 is endocytosed and, together with endosomal TLR3, signals through the IRF pathway, leading to Type I interferon production. MD2, TRAM and TIRAP are adaptor proteins.

TRIF-dependent pathway (TLR3 and 4), generally mediating inflammatory and anti-viral responses respectively. ${ }^{29,30}$

TLRs are crucial for their role in the innate immune system in fighting infection. They are responsible for the initial response to pathogens and their activity drives the generation of innate and adaptive immune responses. Innate immunity begins with the recognition of PAMPs through TLRs by antigen presenting cells (APCs), mainly dendritic cells (DCs) in the peripheral tissues. ${ }^{23}$ Binding of TLR ligands on dendritic cells initiates a downstream signaling cascade that initiates DC maturation. This process is characterized by the production of proinflammatory cytokines (TNF- $\alpha$, IL-6 and IL-12), upregulation of costimulatory molecules (CD40, CD80 and CD86), increased antigen-presenting capacity, and DC migration from the peripheral tissues to draining lymph nodes. ${ }^{23}$ There, antigen presenting DCs stimulate naïve T-cells which begins the adaptive immune response. B-cells also express TLRs and present antigen upon activation, resulting in antibody production specific for the encountered antigen. Since T- and B-cell maturation is influenced by TLR, costimulatory, and cytokine signaling, TLR agonists play an important role in establishing the type of cellular and humoral immune response that is generated.

\section{- TLR Agonist Conjugates}

Due to their pivotal role in both the innate and adaptive immune system, agonists for TLRs have emerged as therapeutic agents, including as adjuvants in vaccines. Adjuvants function by activating immune cells exposed to antigen. Thus, the characteristics of efficacious adjuvants follow different design principles than traditional drugs. As reviewed by $\mathrm{Wu}^{31}$, an effective adjuvant should have a higher retention time at the site of administration to promote local immune system stimulation and prevent potentially harmful, off-target inflammation.

In their review, $\mathrm{Xu}$ and Moyle ${ }^{32}$ state that direct conjugation of TLR agonists to antigen fulfills these requirements by ensuring co-delivery of antigen and adjuvant to immune cells. This enhances the generation of antigen-specific immune responses and prevents wasted inflammation. ${ }^{33}$ In addition, TLR agonists-conjugates have been used as chemical tools to study the role of TLR signaling in immune responses, which was recently reviewed by Oosenbrug and coworkers ${ }^{34}$. However, conjugation of TLR to antigens or other molecules requires thoughtful consideration in choice of TLR agonist, chemical linkage strategy, and site of conjugation. Here, we review conjugation of TLR agonists from a chemistry perspective to provide insight for future applications. 


\section{$>$ TLR2}

The TLR2 subfamily is unique amongst TLRs in that it forms heterodimers with either TLR1 or TLR6 instead of homodimers (Fig. 2A). TLR2 is involved in the recognition PAMPs from a wide range of pathogens, including bacteria, viruses and fungi. ${ }^{35}$ The prototypical agonists to TLR2, however, are a class of bacterial di- or tri-acylated lipoproteins and lipopeptides and their synthetic analogues with $\mathrm{N}$-terminal di- or tripalmitoylated cysteine residues $\left(\mathrm{Pam}_{2} \mathrm{Cys}, \mathrm{Pam}_{3} \mathrm{Cys}\right.$ respectively) (Fig. 2B). $\mathrm{Pam}_{2} \mathrm{Cys}$ and $\mathrm{Pam}_{3} \mathrm{Cys}$ bind TLR2 via two ester bound palmitoyl chains, whereas $\mathrm{N}$-terminal acylation determines TLR1 or TLR6 specificity; an N-terminal fatty acid recruits TLR1 and a free N-terminal amine recruits TLR6 (Fig. 2A). ${ }^{36}$ They often contain the peptide-motif $\mathrm{SK}_{4}$, which enhances the agonists' adjuvanticity and water-solubility. ${ }^{37}$ Isomerically pure R-epimers of $\mathrm{Pam}_{2} \mathrm{CSK}_{4}\left(\mathrm{EC}_{50}:<1 \mathrm{nM}\right)$ and $\mathrm{Pam}_{3} \mathrm{CSK}_{4}\left(\mathrm{EC}_{50}: 5 \mathrm{nM}\right)$ are more potent TLR2 agonists than their racemic mixtures ( $\mathrm{EC}_{50}: 1 \mathrm{nM}$ and $20 \mathrm{nM}$ respectively), due to lower activity of the S-epimers. ${ }^{38,39}$ Because of their ability to induce robust maturation of DCs and effective humoral and cellular responses. ${ }^{40}$, these lipopeptides have been employed as adjuvants in many vaccine studies, even predating the discovery of TLRs. ${ }^{41}$

$\mathrm{Pam}_{2} \mathrm{Cys}$ and $\mathrm{Pam}_{3} \mathrm{Cys}$ and their derivatives are the TLR2 agonists most often found in bioconjugates due to their welldefined chemical structure, ease of production, and the absence of natural endotoxins (Table 1). One exception is the TLR2TLR6 ligand, lipoteichoic acid (LTA), a major component of the gram-positive bacterial cell wall. ${ }^{42}$ LTA was conjugated to both CpG oligodeoxynucleotides (ODN) $1826^{43,44}$, a TLR 9 agonist, and to the cell surface of Lewis Lung Carcinoma (LLC) cells $^{45}$ via a poly-ethylene glycol (PEG) linker. In both instances, conjugation of LTA was achieved by amide bond formation of the primary amines of side-chain D-alanines with $\mathrm{N}$-hydroxysuccinimide (NHS) esters on heterobifunctional linkers. Despite its high potency, LTA has not been used in bioconjugation as extensively as $\mathrm{Pam}_{2} \mathrm{Cys}$ and $\mathrm{Pam}_{3} \mathrm{Cys}$ as endotoxin free LTA is difficult to produce and is therefore expensive. Moreover, the aforementioned conjugation strategies for LTA yield a mixture of high molecular weight, structurally diverse LTA-conjugates. Conversely, $\mathrm{Pam}_{2} \mathrm{Cys}$ and $\mathrm{Pam}_{3} \mathrm{Cys}$ are synthetically accessible and their conjugates can be made structurally homogenous.

Triacylated TLR2-TLR1 agonists $\mathrm{Pam}_{3} \mathrm{Cys}$ and $\mathrm{Pam}_{3} \mathrm{CSK}_{4}$ have been used extensively as conjugates to create selfadjuvanting vaccines. For instance, $\mathrm{Pam}_{3}$ Cys on the $\mathrm{N}$-terminus of $N$. meningitidis lipoproteins greatly enhances the humoral response to Trumenba, an FDA approved, self-adjuvanting $N$. meningitidis vaccine. ${ }^{46,47} \mathrm{Pam}_{3} \mathrm{Cys}$ and its derivatives are readily synthesized, structurally well-defined, commercially available, and do not suffer from the drawbacks associated with LTA. Conjugation with these compounds mainly proceeds through the C-terminal carboxyl group to avoid perturbation of $\mathrm{N}$-terminal lipid interactions with the receptors (Fig. 2B). The incorporation of $\mathrm{Pam}_{3} \mathrm{Cys}$ and $\mathrm{Pam}_{3} \mathrm{CSK}_{4}$ into peptide-based vaccines can easily be achieved through standard solid-phase peptide synthesis (SPPS), placing $\mathrm{Pam}_{3} \mathrm{Cys}$ at the $\mathrm{N}$-terminus of the peptide. Jung and coworkers were the first to apply this strategy for the synthesis of a peptide-based antigen-adjuvant conjugate. ${ }^{41}$ Conjugation of $\mathrm{Pam}_{3} \mathrm{Cys}$ to peptide antigens greatly increases antigen uptake, processing, and presentation ${ }^{48}$
A.
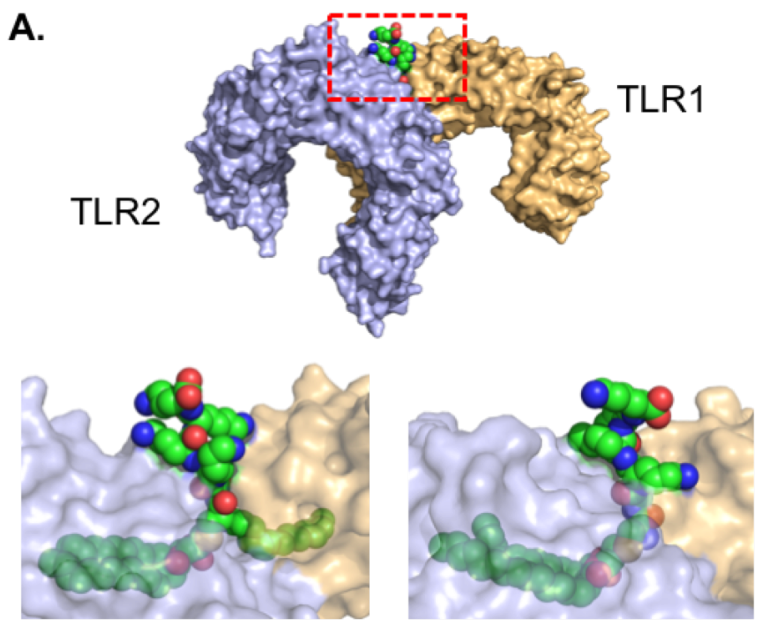

TLR1/2-Pam ${ }_{3} \mathrm{CSK}_{4}$

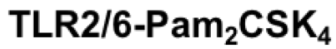

B.

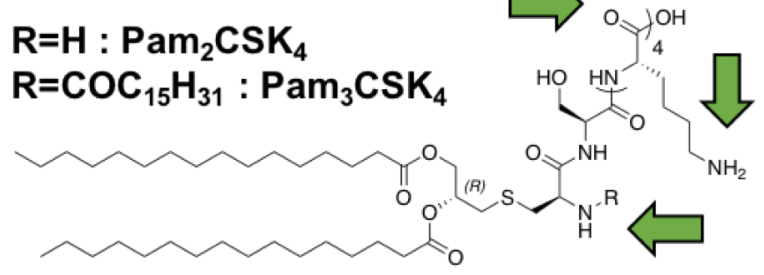

Figure 2. TLR2 agonists bind dimers of either TLR2-TLR1 or TLR2-TLR6. (A) Crystal structure of human TLR2-TLR1$\mathrm{Pam}_{3} \mathrm{CSK}_{4}$ (PDB: 2Z7X). Red rectangle represents area of zoomed view of $\mathrm{Pam}_{3} \mathrm{CSK}_{4}$ binding to TLR2-TLR1. The analogous view from the TLR2-TLR6-Pam ${ }_{2} \mathrm{CSK}_{4}$ crystal structure is also shown (PDB: 5IJC). In both cases, the peptide C-terminus is solvent exposed. TLR2 shown in blue, TLR1 and TLR6 in orange, lipopeptides in green. TLRs in zoom view are shown at $40 \%$ transparency. (B) Chemical structure of $\mathrm{Pam}_{2} \mathrm{CSK}_{4}$ and $\mathrm{Pam}_{3} \mathrm{CSK}_{4}$. Green arrows highlight sites of conjugation.

and leads to enhanced humoral ${ }^{41,49}$ and cellular ${ }^{50}$ immune responses. Zeng et $a l .{ }^{51}$ explored how the positioning of $\mathrm{Pam}_{3} \mathrm{Cys}$ in a peptide-conjugate affects the conjugates pharmacodynamic and immunogenic properties. Placing $\mathrm{Pam}_{3} \mathrm{Cys}$ in the middle of the peptide sequence dramatically increased the conjugates solubility and its ability to induce epitope-specific antibodies compared to terminally conjugated Pam $_{3}$ Cys, Similar results were obtained for TLR2-TLR6 agonist $\mathrm{Pam}_{2} \mathrm{Cys}^{51}$, providing a powerful alternative to linear conjugation of lipopeptide TLR2 agonists.

Preparation of glyco(lipo)peptide conjugates of $\mathrm{Pam}_{3} \mathrm{Cys}$ via SPPS has proven difficult. Issues with separation of the glyco(lipo)peptide conjugate after resin cleavage ${ }^{49}$ and lack of orthogonality between carbohydrate deprotection reagents and palmitoyl esters lead to alternative, convergent synthesis strategies. Several methods to create multi-component vaccines that contain the tumor-associated carbohydrate antigen (TACA) MUC1, a T-helper epitope, and $\mathrm{Pam}_{3}$ Cys have been reported. The Boons lab has employed native chemical ligation $(\mathrm{NCL})^{49,52}$ to sequentially conjugate TACA MUC1 to a Thelper peptide epitope and $\mathrm{Pam}_{3} \mathrm{CSK}_{4}$. Other approaches involve functionalization of the C-terminus of $\mathrm{Pam}_{3}$ Cys with a functional handle, such as alkynes ${ }^{53,54}$, a bromo- or iodoacetyl group $^{55}$, or a pentafluorphenyl-activated ester ${ }^{56,57}$, followed by conjugation to peptides and glycopeptide. Together, these 
Table 1. Overview of TLR1, 2, 3, 4, 5, and 6 agonist conjugates

\begin{tabular}{|c|c|c|c|c|c|}
\hline TLR & Agonist & Conjugation site & Conjugation chemistry & Conjugated to & Ref. $^{a}$ \\
\hline \multirow[t]{4}{*}{ TLR1/2 } & $\mathrm{Pam}_{3} \mathrm{Cys}$ & C-terminus cysteine & SPPS, NCL, CuAAC & $\begin{array}{l}\text { Peptide, } \\
\text { glycopeptide }\end{array}$ & $\begin{array}{l}{[132,166] ;} \\
{[49,52] ; 54}\end{array}$ \\
\hline & \multirow[t]{2}{*}{$\mathrm{Pam}_{3} \mathrm{CSK}_{4}$} & C-terminus lysine & SPPS, thioether bond & $\begin{array}{l}\text { Peptide, } \\
\text { glycopeptide }\end{array}$ & $\begin{array}{l}{[39,48,50] ;} \\
55\end{array}$ \\
\hline & & $\begin{array}{l}\varepsilon-\mathrm{NH}_{2} \text { group lysine } \\
\text { SKKKK } \underline{\text { }}\end{array}$ & CuAAC & $\begin{array}{l}\text { Glycopeptide } \\
\text { antigen }\end{array}$ & 167 \\
\hline & Amplivant & C-terminus lysine & SPPS & Peptide & 64 \\
\hline TLR2 $^{\mathrm{b}}$ & Lipoamino acids & $\mathrm{N}$ - and C-terminus & SPPS & $\begin{array}{l}\text { Peptide and } \\
\text { glycopeptide } \\
\text { antigens }\end{array}$ & $\begin{array}{l}69,132,168- \\
170\end{array}$ \\
\hline \multirow[t]{2}{*}{ TLR3 } & \multirow[t]{2}{*}{ Poly(I:C) } & $\mathrm{NH}_{2}$ of any cytosine & $\begin{array}{l}\text { Bisulfite catalysed } \\
\text { transamination }\end{array}$ & Polysaccharide & 78 \\
\hline & & 5 ' termini & Phosphoramidate coupling & Nanoparticles & 82,83 \\
\hline \multirow[t]{4}{*}{ TLR4 } & \multirow[t]{3}{*}{ MPLA } & $\begin{array}{l}\text { Reducing end } \\
\text { anomeric centre }\end{array}$ & Amide, CuAAC & Oligosaccharide & $\begin{array}{l}{[98-} \\
100,102] ; \\
{[101,171,172]}\end{array}$ \\
\hline & & $\begin{array}{l}\text { Non-reducing end } 6 \\
\text { position }\end{array}$ & $\mathrm{CuAAC}$ & Oligosaccharide & 101 \\
\hline & & Any free $-\mathrm{OH}$ group & Carbamate & Protein & 97 \\
\hline & Pyrimido-indole & Carboxamide group & Amide & $\begin{array}{l}\text { Polymer, TLR7/8- } \\
\text { and } 9 \text { agonists }\end{array}$ & $13,43,107$ \\
\hline TLR5 & Flagellin & $\begin{array}{l}\text { N- or C-terminus, or } \\
\text { D3 domain }\end{array}$ & Fusion proteins & Various proteins & Review $^{32}$ \\
\hline \multirow[t]{7}{*}{ TLR2/6 } & \multirow[t]{2}{*}{$\mathrm{Pam}_{2} \mathrm{Cys}$} & C-terminus & SPPS, amide, CuAAC & $\begin{array}{l}\text { Polymers, } \\
\text { peptide, } \\
\text { glycopeptide, } \\
\text { TLR7- and NOD2 } \\
\text { agonists }\end{array}$ & $\begin{array}{l}{[49,132] ;} \\
173-176] ; \\
177\end{array}$ \\
\hline & & $\mathrm{N}$-terminus cysteine & Amide & $\begin{array}{l}\text { Fluorophore, } \\
\text { chelating agent }\end{array}$ & 60 \\
\hline & MALP-2 & C-terminus & Amide & Glycopeptide & 62 \\
\hline & \multirow[t]{3}{*}{$\mathrm{Pam}_{2} \mathrm{CSK}_{4}$} & C-terminus lysine & Amide, SPPS & $\begin{array}{l}\text { TLR7 and } 9 \\
\text { agonists }\end{array}$ & {$[44,173] ; 178$} \\
\hline & & $\begin{array}{l}\varepsilon-\mathrm{NH}_{2} \text { of lysine } \\
\text { SKKKKK }\end{array}$ & Amide & TLR7 agonist & 173 \\
\hline & & $\mathrm{N}$-terminus cysteine & Thiourea, carbamate bond & $\begin{array}{l}\text { Fluorophore, } \\
\text { photocage }\end{array}$ & $178 ; 108$ \\
\hline & LTA & $\mathrm{NH}_{2}$ of any D-alanine & Amide & $\begin{array}{l}\text { LLC cells, TLR9 } \\
\text { agonist }\end{array}$ & $45 ; 44$ \\
\hline
\end{tabular}

${ }^{a}$ References are clustered and ordered by conjugation chemistry.

${ }^{b}$ TLR2 ligands for which the co-receptor is unknown.

examples show that $\mathrm{Pam}_{3}$ Cys retains its potency in conjugates and that its conjugation is relatively straightforward in peptidebased conjugates, but more demanding in glycopeptide conjugates.

Conjugates of $\mathrm{Pam}_{3} \mathrm{Cys}$ can suffer from poor solubility in aqueous solutions and can therefore be difficult to dose and formulate in vaccines ${ }^{51}$. $\mathrm{Pam}_{2} \mathrm{Cys}$, a synthetic analogue of the N-terminal lipopeptide motif of MALP-2, has a free amino group in place of the N-terminal palmitoyl chain in $\mathrm{Pam}_{3} \mathrm{Cys}$ resulting in improved solubility characteristics and increased potency towards splenocytes ${ }^{58}$ and macrophages ${ }^{59}$. The free amino group of $\mathrm{Pam}_{2} \mathrm{Cys}$ has also been used as a conjugation handle. After introducing a PEG spacer at the N-terminus, Vagner and coworkers conjugated relatively bulky functionalities, such as a chelating agent and fluorescent dyes, the N-terminal amine of $\mathrm{Pam}_{2} \mathrm{Cys}$ while retaining relatively high TLR2-TLR6 potency. ${ }^{60}$ In contrast, conjugation of photocage 2-(2-nitrophenyl)propyl chloroformate to the $\mathrm{N}$ terminal primary amine without a spacer dramatically decreases the activity of $\mathrm{Pam}_{2} \mathrm{CSK}_{4}{ }^{61}$ These results suggest that the $\mathrm{N}$ terminus of $\mathrm{Pam}_{2} \mathrm{Cys}$ can be used for conjugation, but that a chemical spacer may be necessary to retain potency towards TLR2-TLR6. Similar to $\mathrm{Pam}_{3}$ Cys, conjugation of $\mathrm{Pam}_{2}$ Cys can also be accomplished by $\mathrm{C}$-terminal conjugation, as was done in a conjugate of MALP-2 and MUC- $1^{62}$. 
Many structure-activity relationship (SAR) studies into $\mathrm{Pam}_{2} \mathrm{Cys}$ and $\mathrm{Pam}_{3} \mathrm{Cys}$ have been performed in order to optimize their adjuvant properties. These studies have resulted in several TLR2 agonist analogues with interesting chemical and immunological properties, but some of these have not yet been used in bioconjugates. By replacing the N-terminal palmitoyl amide-linkage of $\mathrm{Pam}_{3} \mathrm{Cys}$ for a urea-linkage, Willems and coworkers synthesized a $\mathrm{Pam}_{3}$ Cys analogue called Upam (trademarked by Isa pharmaceuticals as Amplivant) that was shown to be a stronger inducer of DC maturation than Pam $_{3}$ Cys. ${ }^{63}$ Analogous to $\mathrm{Pam}_{3} \mathrm{Cys}$, Amplivant was Cterminally conjugated to a human papillomavirus (HPV) synthetic long peptide (SLP) vaccine and enhanced HPV antigen-specific cellular immune responses in ex vivo stimulated cervical tumour material. ${ }^{64}$ Similarly, Wu et al. have synthesized a $\mathrm{Pam}_{3} \mathrm{Cys}$ analogue with amide-linked palmitoyl chains (SUP3) and showed it was a superior adjuvant in an in vivo tumour challenge model. ${ }^{65}$ Both of these $\mathrm{Pam}_{3} \mathrm{Cys}$ analogues benefit from resistance to esterases, which is hypothesized to contribute to their adjuvanticity. ${ }^{65}$ Although SUP3 has not been used in antigen-conjugates so far it could be an excellent adjuvant for use in self-adjuvanting vaccines and perhaps even superior to $\mathrm{Pam}_{3}$ Cys. Alternatively, Salunke et al . have reported on potent mono-palmitoylated lipopeptide analogues specific to human TLR2. ${ }^{66}$ These analogues are simpler in structure and synthetically more accessible than $\mathrm{Pam}_{3} \mathrm{Cys}$, but have not been in conjugates as of yet despite their attractive properties. We suggest that any conjugation should proceed through the C-terminus, analogous to conjugations of $\mathrm{Pam}_{2} \mathrm{Cys}$ and $\mathrm{Pam}_{3}$ Cys.

An important consideration for the conjugation of lipopeptide TLR2 agonists are the biophysical effects accompanying the hydrophobic lipid chains. PamCSK $4, \mathrm{Pam}_{2} \mathrm{CSK}_{4}$ and $\mathrm{Pam}_{3} \mathrm{CSK}_{4}$ can self-assemble into micelles in aqueous solution. ${ }^{67}$ These self-assembly characteristics have been exploited in selfadjuvanting vaccines where lipopeptides are used as both adjuvant and delivery vehicle. Moyle et al. created multiple group A streptococcus (GAS) vaccines that contained either $\mathrm{Pam}_{2}$ Cys, $\mathrm{Pam}_{3}$ Cys or lipoamino acids, lipidated $\alpha$-amino acids that are believed to activate TLR2 ${ }^{68,69}$ These compounds selfassembled into nanoparticles of a suitable size $(20-200 \mathrm{~nm})$ for passive transport to the draining lymph nodes, which enhanced production of antigen-specific IgG antibodies in vivo ${ }^{68,69}$. Moreover, micellar self-assembly of TLR2 activating lipoproteins in N. Meningitidis vaccine Trumenba is thought to increase the stability of the lipoprotein antigens ${ }^{46}$ ]. However, the self-assembling nature of lipopeptide TLR2 agonists can differ between bioconjugates of different chemical composition. Thus, the biophysical characteristics of a specific lipopeptide-conjugate should be considered as these interactions may affect function.

An alternative to lipopeptide TLR2 agonists are a group of non-lipid TLR2-TLR1 agonists, which were discovered by Guan et al. using high-throughput screening of a chemical library. ${ }^{70}$ Structurally distinct from lipopeptide agonists, these synthetically accessible small molecules display selective potency towards TLR2-TLR1 at concentrations as low as 30 $\mathrm{nM}$, with some of them being selective for either human or mouse TLR1-TLR2. The small molecules have not yet been used in bioconjugates, nor is there any information available on SAR or binding characteristics. Thus conjugation with these agonists would be more exploratory. However, due to their small molecule nature, these TLR2-TLR1 agonists could find use in conjugate applications in which lipopeptide bulk or hydrophobicity would be problematic.

Both large and small molecule agonists have been described for TLR2. In considering a conjugation strategy, the palmitoylated peptide family offers appealing aspects of processability with the $\mathrm{C}$-terminus providing a viable target for most bioconjugation methods. However, biophysical aggregation must be considered. Future work might explore novel ligands containing more simple, hydrophilic chemical motifs to improve accessibility and enhance solubility while avoiding systemic immune activation.

\section{$>$ TLR3}

TLR3 is an endosomal TLR that senses the negatively charged backbone of double-stranded RNA (dsRNA) that is an intermediate in the replication of ssRNA viruses and makes up the genome of some dsRNA viruses (Fig. 3A). ${ }^{71}$ This receptor is unique among TLRs as it signals solely through the TRIF pathway. The commonly used TLR3 agonist is a high molecular weight synthetic dsRNA analogue, polyinosinic-polycytidylic acid $(\operatorname{poly}(\mathrm{I}: \mathrm{C})){ }^{72}$ Poly(I:C) is a potent stimulator of conventional DCs (cDCs) and effector T-cell responses. ${ }^{73}$ However, its development as a vaccine adjuvant has been hampered by its in vivo toxicity at high doses ${ }^{9}$, which have been partially attributed to additional signaling through cytosolic PRRs MDA-5 and RIG-1 in addition to TLR3. ${ }^{74}$ These effects could potentially be mitigated by poly(I:C) conjugation with other compounds. Alternative dsRNA TLR3 agonists IPH$3102^{75}$, Rintatolimod ${ }^{76}$ (poly-IC $\mathrm{IC}_{12} \mathrm{U}$ ) and poly-ICLC ${ }^{77}$ show reduced toxicity but have not been used as TLR-conjugates as of yet.

Despite the clinical potential for TLR3 agonist conjugates, few examples exist of poly(I:C)-conjugates (Table 1). Huang et al. conjugated commercially available poly(I:C) to a protein antigen by introducing linkers on the cytosine primary amines using sodium bisulfite catalyzed transamination reactions. ${ }^{78}$ This strategy invariably leads to a heterogeneous mixture of conjugates however, as there are multiple cytosines within a poly(I:C) molecule. Although they have not been directly compared in a study, we speculate, that conjugation on the nucleobases of poly(I:C) is more likely to disrupt binding to TLR3 than conjugation to the termini, due to the fact that dsRNA binding to TLR3 requires a stretch of at least 40-50 unobstructed base pairs (Fig. 3A). ${ }^{79}$ To conjugate poly(I:C) with its termini, one can employ phosphoramidate chemistry on terminal 5'-phosphates (Fig. 3B). ${ }^{80,81}$ This technique was used by Shukoor et al. to conjugation poly(I:C) to $\gamma-\mathrm{Fe}_{2} \mathrm{O}_{3}$ nanoparticles with its 5' terminal phosphates ${ }^{82,83}$.

Zhang et al. recently reported ${ }^{84}$ on the only known class of small molecule TLR3 agonists. Their lead compound, CUCPT17e, is a weakly potent human TLR3 agonist $\left(\mathrm{EC}_{50}: 4.8\right.$ $\mu \mathrm{M})$ and can also signal through human TLRs $8\left(\mathrm{EC}_{50}: 13.5\right.$ $\mu \mathrm{M})$ and human TLR9 $\left(\mathrm{EC}_{50}: 5.7 \mu \mathrm{M}\right)$, while signaling through murine TLRs was not investigated in this study. CU-CPT17e and its analogues could be a useful alternative to poly(I:C) in conjugates that require small molecule TLR3 agonists. However, SAR studies show that alterations to the structure of CU-CPT17e consistently leads to abrogation of TLR3 potency ${ }^{84}$, complicating the successful conjugation of this small molecule TLR3 agonist. Alternatively, studies have shown that nucleic acid based adjuvants can be associated with various molecules, including antigens, through electrostatic interactions 
A.
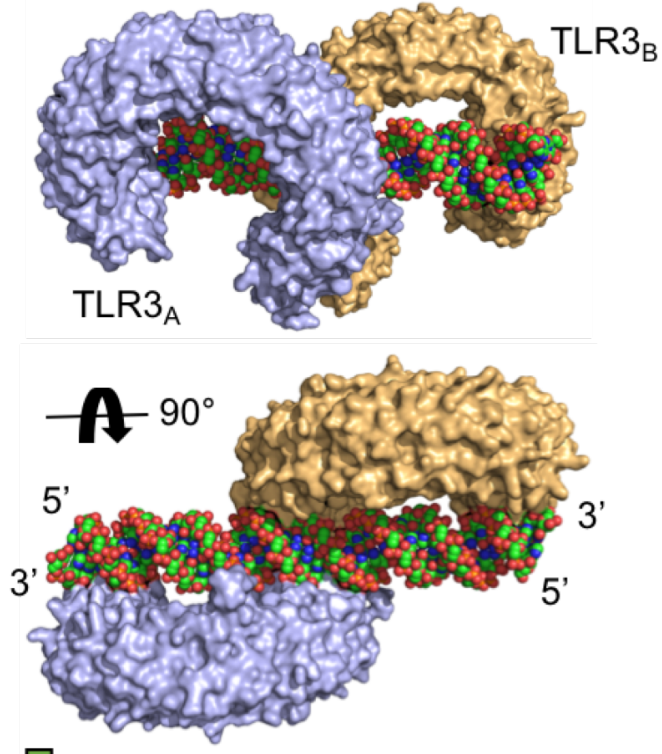

B.

TLR3-dsRNA
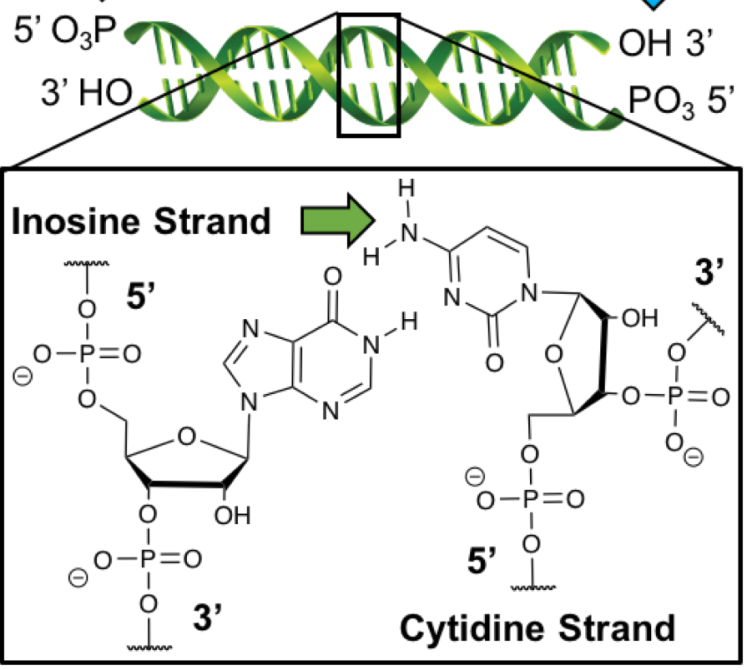

Figure 3. TLR3 agonists are dsRNAs that bind to TLR3 dimers. (A) Crystal structure of mouse TLR3-dsRNA (PDB: $3 \mathrm{CIY})$. The receptors bind to the negatively charged backbone of the dsRNA molecule. TLR3 shown in blue and orange, dsRNA shown in green. (B) Carton structure of dsRNA with sites that have been conjugated highlighted by green arrows and suggested sites of conjugation by blue arrows.

with the backbone phosphates. Zhang et al. demonstrated this technique to form polyelectrolyte multilayer vaccines composed of poly(I:C) and cationic ovalbumin (OVA) peptide antigens which stimulated robust $\mathrm{T}$ cell responses. ${ }^{85}$ Follow up studies further characterized these materials and their ability to generate powerful immune responses. ${ }^{86,87}$

In conclusion, TLR3 has a unique signaling pathway and immunological activity but has been limited in application due to a lack of agonists. Although highly potent, commercially available dsRNA TLR3 agonists are bulky, polydisperse and difficult to characterize using conventional chemical analysis techniques. Conjugation of prototypical TLR3 agonist poly(I:C) can proceed by introducing chemical handles to cytosines along its backbone. However, we suggest that the terminal ends of dsRNA analogues may be better sites for conjugation based on site availability as suggested by crystal structure analysis and the homogenous nature of such a compound. The recently reported class of small molecule TLR3 agonists are attractive due to their small molecule nature, but they are considerably less potent towards TLR3 than poly(I:C). Thus, the field would benefit from the discovery of novel, potent small-molecule ligands that are exclusive agonists of TLR3 and can be modified to generate bioconjugates.

\section{$>$ TLR4}

TLR4 was the first human TLR identified to bind a ligand, by Poltorak et $a l^{88}$ and Hoshino et $a l^{89}$, and is the most studied among the TLR family. TLR4 binds ligands with the aid of myeloid differentiation factor 2 (MD2), forming a TLR4-MD2agonist complex (Fig. 4A) $)^{90}$ TLR4 is unique among TLRs in that upon ligand binding, it can signal through both the MyD88 and TRIF pathways (Fig. 1), resulting in a variety of accessible immune response profiles. ${ }^{91}$ Some TLR4 agonists bias particular signaling pathways, presumably through differing conformational changes and cellular location upon receptor binding, resulting in unique immune responses. ${ }^{92}$ Thus, tuning the chemical structure of these agonists impacts the immunological activity of the compound. Its main natural binding ligands are lipopolysaccharides (LPS), major components of the Gram-negative bacteria cell membrane responsible for bacterial sepsis (Fig. 4A). ${ }^{90}$ Although many forms of LPS exist, the toxicity of these molecules has prevented their use in vaccines. However, several groups, notably Qureshi et al. ${ }^{93}$, developed a detoxified analog of LPS, monophosphoryl lipid A (MPLA), which is now FDA approved as an adjuvant in multiple vaccines and is currently in several clinical trials. $^{94}$ The diversity in chemical composition and immunological activity of TLR4 agonists presents opportunity for chemical manipulation in a variety of TLR conjugate applications (Table 1).

The glycolipid moiety in LPS-derived TLR4 agonists contains several sites for modification. MPLA was the first example of an intentionally modified LPS derivative and has since been used heavily as a vaccine adjuvant. MPLA is the lipid A component of LPS, but lacking the reducing end phosphate, which decreases the toxicity over 1000-fold (Fig. 4B) ${ }^{95}$ The reduction in toxicity has been attributed to the bias of activation toward the TRIF pathway over MyD88 pathway, resulting in less pro-inflammatory cytokine production. ${ }^{96}$ Modifications that bias activity have been further exploited to tune the immunomodulatory properties of the agonist. For example, Carter and coworkers have described glucopyranosyl lipid adjuvant (GLA) and second-generation lipid adjuvant (SLA), MPLA analogues with varying lipid chain lengths that elicit distinct immunological responses and activate both mouse and human TLR4 ${ }^{92}$ Although these modifications can be used to tune the immune response, they are not sites amenable to conjugation chemistry as this portion of the molecule directly binds to the MD2-TLR4 complex (Fig. 4B).

Although the hydrophobic portions of glycolipid TLR4 agonists are not ideal sites of conjugation, the exposed functional groups of the sugars have been used as conjugation handles. In one example, Schülke et al reacted MPLA with carbonyldiimidazole (CDI) followed by OVA to form a nonspecific MPLA-OVA conjugate. ${ }^{97}$ The conjugation resulted in boosted immune responses toward OVA compared to the mixture of unconjugated MPLA and OVA. In another example, 
A.
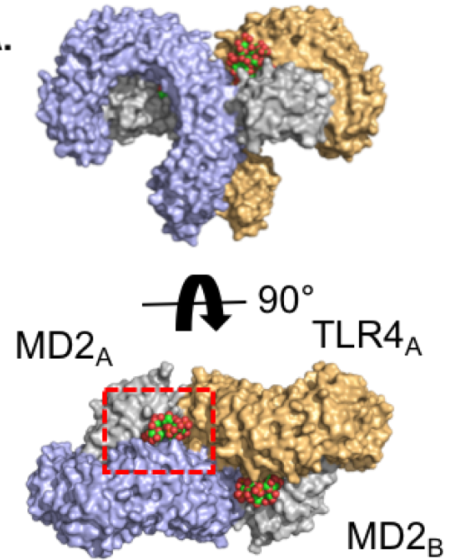

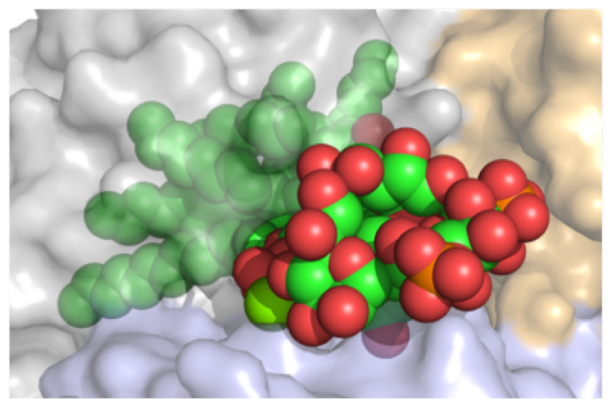

TLR4-MD2-LPS

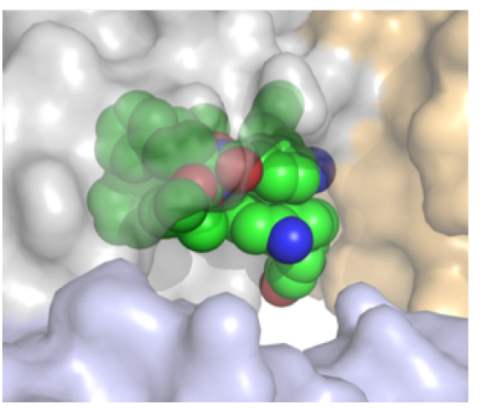

TLR4-MD2-Neoseptin-3

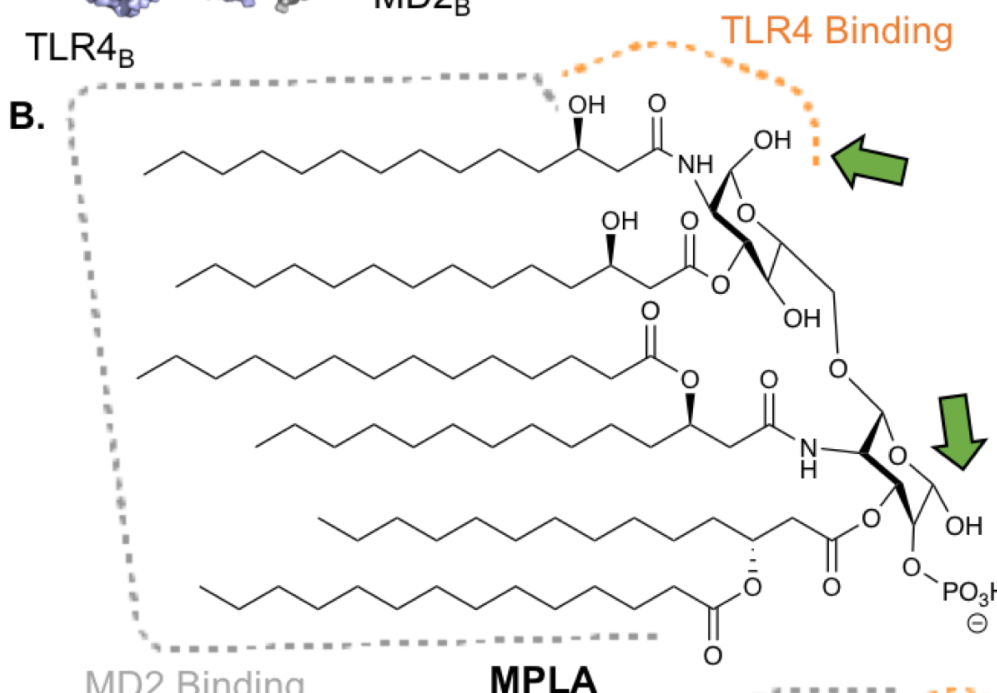<smiles>CC(C)(C)OC(=O)[C@H](CCc1ccccc1)NC(=O)c1ccc(N)c(CCc2ccc(O)cc2)c1</smiles>

$\ominus$

Neoseptin-3 (x2)

MD2 Binding

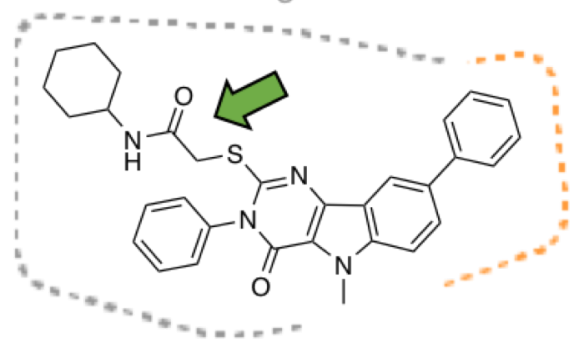

Pyrimido[5,4-b]indole (Compound 26)

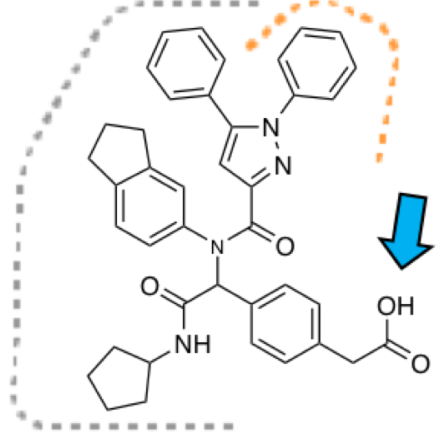

Ugi Compound (AZ617)

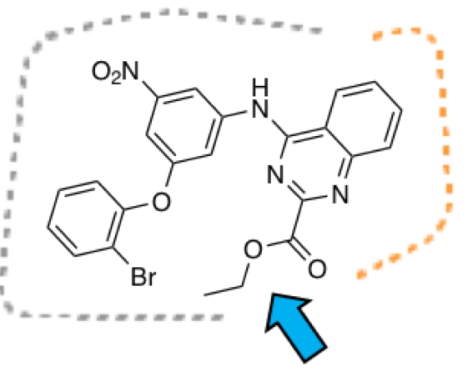

4-aminoquinazoline (Compound 1a)

Figure 4. TLR4 agonists bind MD2 and TLR4. (A) Crystal structure of human TLR4-MD2-LPS (PDB: 3FXI) from two viewpoints (left), red rectangle depicts zoom view of LPS binding (middle) in which proteins are shown with $40 \%$ transparency. The analogous view from the mouse TLR4-MD2-Neoseptin-3 crystal structure is also shown (PDB: 5IJC, right). TLR4 shown in blue and orange, MD2 shown in gray, LPS and Neoseptin-3 shown in green. (B) Chemical structures of various TLR4 agonists. Areas that bind MD2 (dotted gray) and TLR4 (dotted orange) shown. Green arrows highlight previous sites of conjugation, blue arrows highlight suggested sites of conjugation.

Guo and coworkers developed a synthetic strategy to afford an MPLA derivative with an amino linker appended to the nonreducing hydroxyl group. ${ }^{98-100}$ Conjugates of this derivative with TACAs via amide bond formation afforded selfadjuvanting, glycoconjugate cancer vaccines. Recently, Wang et al. did a SAR study on MPLA conjugation to a lipoarabinomannam oligosaccharide and found that nonreducing 6 '-hydroxyl conjugates had superior immunological activity to 1-O-conjugates. ${ }^{101}$ The Guo lab also used 6'- hydroxyl conjugation of MPLA to produce an MPLA-Group C Meningitis glyco-antigen-conjugate vaccine. ${ }^{102}$ Although the synthetic method developed in this study resulted in 10-100's of $\mathrm{mg}$ of MPLA derivatives amenable to a variety of conjugation strategies, the approach requires expertise in synthetic organic carbohydrate chemistry, which may not be present in many vaccine development teams. If covalent conjugation is not an option, non-covalent co-delivery strategies for MPLA and antigen could be considered. Several 
studies have reported enhanced adjuvant effects when incorporating glycolipid TLR4 agonists into emulsions, including some FDA approved vaccines, a straightforward strategy given the hydrophobicity of the compounds. ${ }^{103-105}$ Thus, small molecules may be more advantageous for applications involving direct chemical linkage for the greater ease in chemical manipulation and hydrophilicity.

Recently, a variety of small molecule TLR4 agonists bearing little structural resemblance to glycolipids have been developed. These include pyramido-[5,4-b]indoles, 4aminoazoquinolines, $\alpha$-aminoacyl amide "Ugi products," and neoseptins. Given their synthetically accessible nature, these molecules are more amenable to functionalization for various applications. However, all of these molecules bind predominantly within the MD2 pocket, making it difficult to introduce chemical modifications without sacrificing agonist potency (Fig. 4B). Therefore, it is critical to evaluate the site of modification before embarking on a synthetic route to obtain the desired conjugate.

The pyramido-[5,4-b]indoles were discovered by Chan and coworkers via high throughput screening in $2013 .{ }^{106}$ The hit compound in this study (Compound $28, \mathrm{EC}_{50}: 1-10 \mu \mathrm{M}$ ) was shown to stimulate high production of IP-10/CXCL10 and IL-6 in vitro. Variations of this molecule have been used in conjugation studies, including multi-valent TLR conjugates, by introducing a linker on the carboxamide moiety. ${ }^{43,107}$ In another study, Lynn and coworkers synthesized a derivative of the lead pyramido-[5,4-b]indole compound by adding an amine functionality to a carboxamide cyclohexyl group, which was then conjugated to N-isopropylacrylamide (NIPAM) polymers using a bivalent tetraethylene glycol linker. ${ }^{13}$ In addition, the indole nitrogen has been functionalized with nitroveratryloxycarbonyl (NVOC) to afford a light-activated TLR4 agonist, showing that this site is important for ligand binding despite docking studies suggesting it may be solvent accessible. $^{108}$ More recently, a further optimized pyramido[5,4-b]indole TLR4 agonist (Compound 26, EC 50 : 600 nM, Fig. 4B) was shown to improve and bias human TLR4 activation over mouse TLR4 activation. ${ }^{109}$ Although this molecule has yet to be implemented in conjugation applications, we expect it to behave similarly to the original hit molecule, Compound 28, based on reported docking studies and SAR studies.

The same group discovered substituted 4-aminoquinazoline human TLR4 agonists by high throughput screening in $2014 .^{110}$ The hit compound (Compound $1 \mathrm{a}, \mathrm{EC}_{50}: 2 \mu \mathrm{M}$ ) was predicted to bind in a similar manner as pyramido-[5,4-b]indole compounds in docking studies, despite the lack of structural similarity. SAR studies suggested that the ester moiety may be amenable to derivatization for conjugation applications as functionalization with bulky groups had favorable effects on potency (Fig. 4B). However, docking studies suggested that this site may reside at the interface of TLR4 and MD-2, meaning that conjugation to this site may require a linker to prevent perturbation of TLR4-MD-2 dimerization.

Neoseptin-3 is a peptidomimetic molecule discovered by Wang et al. through screening compounds for activation of TLR4-MD2 in murine macrophages. ${ }^{11}$ Despite the simple design, the molecule has few sites amenable to chemical functionalization due to the unique binding mechanism of the compound. Two Neoseptin-3 molecules bind asymmetrically within the same binding pocket of the TLR4-MD2 complex, a property which is thought to be unique among all studied protein-ligand interactions (Fig. 4A). The Neoseptin-3 aniline moiety appears to be a potential site of conjugation, based on the reported SAR study and crystal structure evaluation (Fig. 4B). However, while one of the molecule's aniline appears to be solvent exposed, the other interacts with TLR4 residues. Hypothetically, stimulation with a 1:1 mixture of conjugated and unconjugated Neoseptin-3 molecules may avoid this issue. However, this strategy may result in little Neoseptin-3conjugate binding if the conjugate affinity for the receptor is lower than unconjugated Neoseptin-3. Thus, Neoseptin-3 conjugation strategies would likely require empirical design and testing to determine effective sites or linkers needed. In addition, Neoseptin-3 only activates mouse TLR4, limiting its practical use.

Marshall et al. developed the human TLR4 stimulating "Ugi compounds" using a combinatorial molecule screen with Ugi multi-component reaction products. ${ }^{112}$ These molecules were highlighted for their high potency and hydrophilicity. One of the lead compounds in the study, AZ617 (Fig. 4B, EC E0 $_{50} 6.3$ $\mathrm{nM})$, was within an order of magnitude of LPS potency $\left(\mathrm{EC}_{50}\right.$ : $2.4 \mathrm{nM}$ ) and exhibited ideal hydrophilicity characteristics. Docking studies suggest that the compound binds in a similar location to other small molecule TLR4 agonists, between MD2 and TLR4. In this case, the free carboxyl group appears to be close to the solvent exposed area of the binding pocket. Thus, conjugation to other molecules, potentially through amide or ester bond formation, might be possible at this site. In fact, some derivatives in SAR studies contained an alkyne substituted for the carboxyl group, among other modifications, making it amenable to click chemistry. However, these compounds suffered a 10-100 fold drop in activity and reduced hydrophilicity compared to AZ617.

Neve and coworkers demonstrated Euodenine A, a natural product isolated from Papua New Guinea Tree, derivatives had low $\mu \mathrm{M}$ affinity for human TLR4. ${ }^{113}$ SAR studies suggest that substituting the methyl group appended to the cyclobutyl moiety in Euodenine A with functional handles for conjugation may be tolerated. However, no docking studies are reported for this molecule, making conjugation attempts to the molecule more empirical relative to other small molecule TLR4 agonists.

In summary, TLR4 agonists have great potential as immunological modulators as demonstrated by their clinical use. These applications could be expanded or improved with TLR4 agonist conjugates. Although most applications have used glycolipid based TLR4 agonists, like MPLA or GLA, these compounds are difficult to conjugate effectively. Alternatively, several small molecule TLR4 agonists exist with a range of chemical structure and potency. However, SAR studies have demonstrated that potency is sensitive to small changes in chemical structure. Thus, TLR4 agonist conjugation strategies could be advanced by developing simplified glycolipid synthesis protocols, reliable modification techniques, and by improved design of small molecules amenable to conjugation. Billod et al. recently reviewed computation based approaches for TLR4 ligand prediction and design, which could aid in the development of TLR4 agonists for conjugation. ${ }^{114}$

\section{$>$ TLR5}

TLR5 resides on the cell membrane and responds to flagellin. ${ }^{115,116}$ Flagellin is a bacterial protein $(\sim 50 \mathrm{kDa})$ that self-assembles to form the flagellum organelle, providing motility for the organism. Recombinant flagellin and modified 
variants are also potent activators of TLR5. ${ }^{117-119}$ TLR5 agonist conjugates have largely been used as recombinant fusion proteins with disease related antigens to generate single molecule vaccines, several of which are in clinical trials (Table 1). ${ }^{120-122}$ Recombinant expression of antigens with fused flagellin may not work in every application. For example, the fused protein may have poor solubility characteristics, compromise antigen expression, block antibody epitopes, or generate immune responses that are not well suited for specific applications. To overcome some of the limitations of flagellinantigen fusion proteins, several studies have shown that codelivery of flagellin-coated nanoparticles and antigen can also be used as effective vaccines. ${ }^{123-125}$ Flagellin has also been conjugated to other compounds through non-site specific cross linking chemistries with surface exposed lysines. ${ }^{118,126-128}$ In these studies, authors have noted that the conjugation approach could be improved by generating flagellin variants which are designed to facilitate conjugation in portions of the protein that are not involved with TLR5 binding.

The only synthetic small molecule agonists for TLR5 are flagellin derived peptides. ${ }^{129}$ These peptides share homology to flagellin's highly conserved D1 binding domain and can be as small as 13 residues in size. To our knowledge, conjugates of flagellin derived peptides have yet to be synthesized for vaccine applications. The flagellin peptide should be amenable to conjugation with other peptides or molecules via traditional SPPS approaches. However, we observed no in vitro activity of TLR5 peptides or TLR5 peptides conjugated with small molecules in initial studies (unpublished data).

\section{$>\quad$ TLR7 and TLR8}

TLR7 and TLR8 agonists are among the most studied of the TLR family. Similar to TLR3 and TLR9, the receptors are located in the endosome and bind nucleic acid-based agonists (Fig. 5A). ${ }^{130}$ However, unlike TLR3 and 9, TLR7 and 8 are expressed across most human immune cell types. This feature has made TLR 7 and 8 targeting adjuvants sought after to generate efficacious $T$ cell responses in human vaccines. ${ }^{131} \mathrm{In}$ addition, most TLR7/8 agonists are effective across many species.

The natural ligands for TLR7 and TLR8 are ssRNAs of viral origin. ${ }^{130}$ Due to the poor drug properties of RNA, several small molecule agonists have been developed, including imidazoquinolines, purine derivatives, and guanosine analogues. ${ }^{75}$ Many of these heteroaromatic molecules are agonists for both TLR7 and TLR8. ${ }^{132}$ However, empirical testing, crystal structure examination, and SAR studies have shed light on the structural requirements for TLR7 or TLR8 agonist specificity. ${ }^{133-135}$ These small molecule agonists have been effectively utilized as immunostimulants in a variety of applications. One synthetic small molecule imidazoquinoline TLR7 agonist, Imiquimod, is approved for clinical use in topical treatment of certain skin cancers, genital warts, and skin conditions. ${ }^{136}$ However, promising results in vitro are often difficult to recapitulate, and even potentially toxic, in vivo. ${ }^{8,137}$ This observation has been attributed to the molecules' pharmacokinetic properties as they rapidly diffuse to the blood stream, resulting in systemic cytokine production and inflammation. ${ }^{31}$ Due the practical issues, yet clinical promise, of TLR7/8 agonists, they have received considerable attention as TLR conjugates (Table 2). The basic chemical structure of these heteroaromatics have multiple sites amenable for functionalization; both a primary and secondary amine are
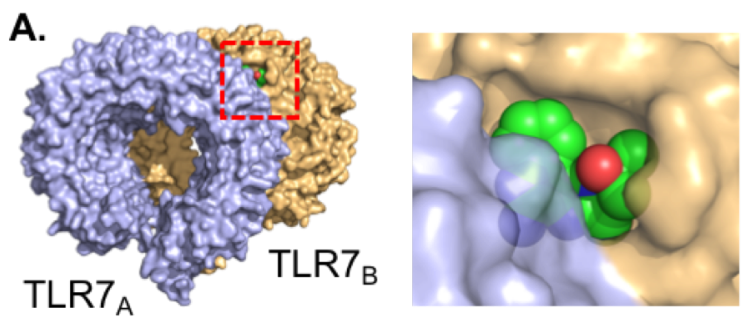<smiles>[B]/C=C\Cn1c(=O)n([C@@H]2OC(CO)C(O)[C@H]2O)c2nc(N)[nH]c(=O)c21</smiles>

Loxoribine
TLR7-Resiquimod<smiles>CCOCc1nc2c(N)nc3ccccc3c2n1CC(C)(C)O</smiles>

Resiquimod

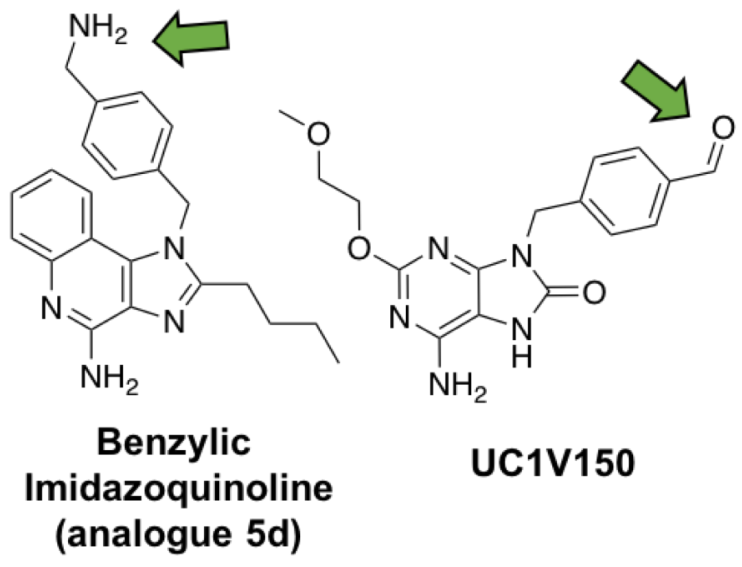

Figure 5. TLR7/8 agonists bind TLR7 and/or TLR 8 homodimers. (A) Crystal structure of monkey TLR7Resiquimod (PDB: 3FXI), red rectangle depicts view of Resiquimod binding (right) in which proteins are shown at $20 \%$ transparency. The molecule bridges the receptors at the interface. TLR7 shown in blue and orange, Resiquimod shown in green. (B) Chemical structures of various TLR7/8 agonists. Green arrows highlight recommended sites of conjugation.

present for conjugation, as well as an aromatic ring system capable of bearing other functional groups. Several conjugation strategies have been successfully employed, but the potency and biological effects of the conjugates varies greatly.

Most adenine analogues found in conjugate applications are tethered through a substituted $\mathrm{N}^{1}$-benzyl linker, based on the potent TLR7 agonist 9-benzyl-8-hydroxy-2-(2-methoxyethoxy) adenine (SM360320). ${ }^{138} \mathrm{Wu}$ and coworkers were the first to synthesize a SM360320 derivative for conjugation by functionalizing the $\mathrm{N}^{1}$-benzyl with an aldehyde moiety. ${ }^{139}$ The resulting TLR7 agonist, UC-1V150 (Fig. 5B), was ligated to hydrazine functionalized mouse serum albumin (MSA), while retaining its TLR7 agonist activity. Another conjugation method, from the same lab, involved using an $\mathrm{N}^{1}$-benzylic carboxylic acid UC-1V150 analogue, which was conjugated to phospholipids, with or without PEG spacers. ${ }^{18}$ Adenine derivatives have also been ligated through $\mathrm{N}^{1}$-alkyl linkages, 
Table 2. Overview of TLR 7, 8, and 9 agonist conjugates

\begin{tabular}{|c|c|c|c|c|c|}
\hline TLR & Agonist & Conjugation site & Conjugation chemistry & Conjugated to & Ref. $^{a}$ \\
\hline \multirow[t]{3}{*}{ TLR7 } & SM360320 & $\mathrm{N}^{1}$-benzyl linkage & Amide, hydrazone & $\begin{array}{l}\text { Polymer, protein, } \\
\text { phospholipid }\end{array}$ & $14 ;[18,139]$ \\
\hline & & $\mathrm{N}^{1}$-alkyl linkage & Amide & Protein & 179 \\
\hline & $\begin{array}{l}\text { 2-alkoxy-8- } \\
\text { hydroxyadenyl } \\
\text { derivative }\end{array}$ & C-2 linkage & $\mathrm{CuAAC}$ & Peptide & 140 \\
\hline \multirow[t]{6}{*}{ TLR7/8 } & $3 \mathrm{M}-012$ & $\mathrm{~N}^{1}$ linkage & $\begin{array}{l}\text { thiol-maleimide, UV light } \\
\text { induced coupling }\end{array}$ & Peptide, protein & $150 ; 149$ \\
\hline & Resiquimod & C-4 linkage & Carbamate linkage & Photocage & 147 \\
\hline & $\begin{array}{l}\mathrm{N}^{1} \text {-benzyl } \\
\text { imidazoquinoline }\end{array}$ & $\mathrm{N}^{1}$-benzyl linkage & $\begin{array}{l}\text { Thiourea, reductive } \\
\text { amination, amide }\end{array}$ & $\begin{array}{l}\text { Flourophore, } \\
\text { protein, TLR } 7 / 8 \\
\text { agonist }\end{array}$ & $142 ; 141 ; 148$ \\
\hline & & $\begin{array}{l}\mathrm{C}-4, \mathrm{~N}^{1} \text {-benzyl, } \mathrm{N}^{1} \text { - } \\
\text { alkyl linkage }\end{array}$ & Amide & Polymer & 13 \\
\hline & $\begin{array}{l}\text { Imidazoquinoline } \\
\text { amino acid }\end{array}$ & $\mathrm{N}$ - and C-terminus & SPPS & Peptide & 155 \\
\hline & Loxoribine & $\mathrm{C}^{\prime} \mathrm{OH}$ of ribose & $\mathrm{CuAAC}$ & $\begin{array}{l}\text { TLR4- and } 9 \\
\text { agonist }\end{array}$ & \\
\hline \multirow[t]{4}{*}{ TLR9 } & Class A CpG & 5' Phosphate & Phosphoramidite & Phospholipid & 20 \\
\hline & Class B CpG & 5' Phosphate & $\begin{array}{l}\text { Thioether, Thiol- } \\
\text { maleimide, } \\
\text { phophoramidite, CuAAC, } \\
\text { bis-aryl hydrazone, } \\
\text { reductive amination, } \\
\text { disulfide }\end{array}$ & $\begin{array}{l}\text { TLR4-, 7/8 and } 9 \\
\text { agonists, } \\
\text { polymers, biotin, } \\
\text { fluorophore } \\
\text { phospholipid, } \\
\text { protein }\end{array}$ & $\begin{array}{l}163 ; \\
{[19,107,180] ;} \\
20 ; 181 ; 165 ; \\
12 ; 15\end{array}$ \\
\hline & Class B CpG & 3' Phosphate & $\begin{array}{l}\text { Amide, thiol-maleimide, } \\
\text { bis-aryl hydrazone }\end{array}$ & $\begin{array}{l}\text { LLC cells, } \\
\text { TLR2/6- and } 4 \\
\text { agonists, peptide, } \\
\text { protein }\end{array}$ & $\begin{array}{l}45 ;[44,48] ; \\
165\end{array}$ \\
\hline & Class C CpG & 5' Phosphate & $\begin{array}{l}\text { Disulfide coupling, } \\
\text { phosphoramidite }\end{array}$ & $\begin{array}{l}\text { Nanoparticles, } \\
\text { phospholipid }\end{array}$ & $15 ; 20$ \\
\hline
\end{tabular}

${ }^{a}$ References are clustered and ordered by conjugation chemistry.

although this resulted in less potent conjugates. Alternatively, Weterings and colleagues have described a method to covalently link a 2-alkoxy-8-hydroxyadenine derivative through an ethylene glycol linked azide on its $\mathrm{C}-2$ position to OVA peptide epitopes. ${ }^{140}$ This adenine derivative was conjugated to a peptide epitope through click chemistry, creating a self-adjuvanting vaccine. Although conjugation of the TLR7 agonist increased presentation of the antigen, it also abolished the induction of DC activation. The authors suggest steric hindrance of the peptide moiety may influence binding of the conjugate to the TLR.

Similar to adenine analogues, conjugation of imidazoquinolines mainly proceeds through benzylic linkages. Shulka and coworkers conjugated an $\mathrm{N}^{1}-(4-$ aminomethyl)benzyl substituted imidazoquinoline (analogue 5d, Fig. 5B) to three fluorescent dyes, fluorescein, rhodamine B, and BODIPY-TR-cavarine, either directly or by first converting the free amine to an isothiocyanate. ${ }^{141}$ In doing so, they created potent, fluorescent probes for TLR7 activation. The same group also ligated $\mathrm{N}^{1}$-(4-aminomethyl)benzyl substituted imidazoquinolines under more mild conditions. By converting the free amine to an isothiocyanate- and maleimidegroup, they conjugated the TLR agonist to both a model peptide and reduced glutathione, in aqueous buffer, without additional

reagents. ${ }^{142}$ The amino group was also reacted directly with a model oligosaccharide under reductive amination conditions. All resulting conjugates were obtained in high yield and preserved their agonistic activity.

Lynn et al. demonstrated ligation of $\mathrm{N}^{1}$-alkyl and $\mathrm{N}^{1}-(4-$ aminomethyl)benzyl substituted (analogue 5d reported previously) TLR 7 agonists. ${ }^{13,143}$ They showed that the benzylic linker (Fig. 5B, $\mathrm{EC}_{50}: 0.1 \mu \mathrm{M}$ ) increased potency of the conjugates 20 -fold compared to the alkyl linker $\left(\mathrm{EC}_{50}: 2 \mu \mathrm{M}\right)$ inspired by previously reported SAR studies. ${ }^{144}$ The benzylic imidazoquinoline compound was conjugated to a N-(2hydroxypropyl)methacrylamide (HPMA) polymer which enhanced its immunological activity in vivo. This effect was achieved by causing accumulation in the draining lymph node instead of diffusion to the bloodstream.

Conjugation of imidazoquinolines through the C-4 amine resulted in a complete loss of agonist activity according to SAR studies $^{145}$ and crystal structures ${ }^{146}$ of TLR8. In one example, a method to gain spatial and temporal control over immune cell activation was demonstrated by photocaging the C-4 amine of Imiquimod and Resiquimod. ${ }^{147}$ The free C-4 amine of the imidazoquinolines was functionalized with 2-(2nitrophenyl)propyl chloroformate (NPPOC-Cl), creating a light-responsive TLR agonist. TLR7/8 agonist dimers linked 
through their C-4 amine also display sharply decreased TLR7 agonist activity compared to $\mathrm{N}^{1}$-benzyl linked dimers. ${ }^{148}$

Willie-Reece and coworkers demonstrated the promise for TLR7/8 agonist-antigen conjugates as a subunit HIV vaccine. ${ }^{149}$ An amine functionalized resiquimod (3M-012) was photocrosslinked with HIV Gag protein. The conjugate was shown to potently stimulate $\mathrm{T}$ and $\mathrm{B}$ cell responses, in mice and non-human primates, toward the antigen whereas the unconjugated mixture did not. A thiol-functionalized 3M-012 was also crosslinked via thiol-maleimide chemistry to HIV envelope protein. ${ }^{150}$ Despite high immunostimulatory activity, the conjugation blocked antibody responses toward certain antigen epitopes. Recently, the same lab demonstrated that protective T cell responses via TLR7/8-antigen conjugates required aggregation of the conjugate. ${ }^{151}$ In addition, Holbrook and coworkers conjugated an amine functionalized Resiquimod to influenza virus via a bifunctional NHS-maleimide peg linker. ${ }^{152}$ This and follow up studies demonstrated the Resiquimodinfluenza conjugate vaccine generated efficacious influenza immunity in non-human primate neonates, a difficult vaccination model. ${ }^{153,154}$ These studies highlight both the clinical potential of TLR7/8 agonist conjugates and the need to development site-specific methods for agonist conjugation to improve antigen-specific immune responses while preserving antigen recognition.

Further broadening the scope of conjugation strategies for TLR7/8 agonists, Fujita and coworkers synthesized an imidazoquinoline-like amino acid, 6-(4-amino-2-butylimidazoquinolyl)-norleucine. ${ }^{155}$ Although weakly potent, the novel amino acid provides a way to easily introduce imidazoquinolines into peptides via SPPS. To create a more potent TLR7/8 agonistic amino acid we speculate that substituting norleucine for phenyl alanine to create 4-((4amino-2-butyl-imidazoquinolyl)methyl) phenylalanine, which contains the $\mathrm{N}^{1}$-benzyl substituent associated with high TLR7/8 agonist activity. Such a highly potent imidazoquinoline-like amino acid would enable facile synthesis of powerful selfadjuvanting vaccines targeting TLR7/8 through SPPS.

$\mathrm{Wu}$ and coworkers have developed a guide to effectively modify imidazoquinoline-like TLR $7 / 8$ agonists to create small molecule immunopotentiators (SMIPs). ${ }^{33}$ They showed that creating an antigen depot effect was key for in vivo adjuvant effectiveness by limiting "wasted inflammation" and directing immune responses toward intended targets. This effect was achieved by making the molecules more lipophilic through conjugation with hydrophobic moieties. However, they found these conjugates were impractical due to scale- and formulation issues caused by poor conjugate solubility. Instead, the group found that by conjugating SMIPs to phosphate-functionalized PEG linkers followed by non-covalent absorption with alum, the depot effect was achieved to yielding effective adjuvants.

Loxoribine is the only guanosine analogue to yet be conjugated. In an effort to synthesize a tri-valent TLR agonist conjugate, a Loxoribine derivative amenable to conjugation was synthesized by substituting the 5' primary alcohol for an azide (Fig. 5B). ${ }^{107}$ The Loxoribine-azide was conjugated to an alkyne-functionalized core molecule through copper(I)catalyzed alkyne-azide cycloaddition (CuAAC). However, whether this conjugation strategy preserves TLR7/8 agonist potency remains uncertain. Conjugation of Loxoribine to a diagonist of CpG ODN (TLR9) and indole (TLR4) did not increase the conjugate's potency, which we attribute to the relatively low potency of Loxoribine.
In summary, TLR7/8 agonists are synthetically accessible, relatively potent, and highly amenable to conjugation. Conjugation of TLR7/8 agonists to phospholipids and polymers has proven to be an effective strategy in improving their pharmacodynamics/pharmacokinetic properties and their conjugation to protein- and peptide antigens creates highly immunogenic self-adjuvanting vaccines. In addition, the synthesis of TLR7/8 agonist conjugates is as the compounds are more amenable to synthetic methods than lipidated TLR4 agonists. Together, these qualities make TLR7/8 agonists appealing immunostimulants for bioconjugation in many applications.

\section{$>\quad$ TLR9}

TLR9 is located in the endosome and senses DNA rich in unmethylated $\mathrm{CpG}$ dinucleotides. TLR9 also binds synthetic CpG oligodeoxynuceotides (ODNs), which are short, singlestranded DNA (ssDNA) oligomers with unmethylated $\mathrm{CpG}$ motifs (Fig. 6A). CpG ODNs induce strong cellular and humoral responses against co-administered antigens, making them highly attractive vaccine adjuvants. ${ }^{156}$ The sequence of the CpG ODN dictates the species specificity of the agonist, with many commercially available varieties developed for human, murine, bovine and other organisms.

$\mathrm{CpG}$ ODNs have been used in bioconjugates for a variety of applications; $\mathrm{CpG}$ ODNs have been conjugated to peptide antigens $^{48}$, antibodies ${ }^{157}$, other TLR agonists ${ }^{43,44,107}$, nanoparticles $^{15,158}$, cancer 'cells ${ }^{45}$ and lipids ${ }^{19,20}$ (Table 2). Conjugation of $\mathrm{CpG}$ ODNs to nanoparticles and lipids can improve pharmacokinetics, pharmacodynamics, and targeting of the adjuvant to draining lymph nodes. ${ }^{12,20}$ Conjugation of $\mathrm{CpG}$ ODNs to antigens can improve antigen uptake, antigen presentation $^{48}$, and cross-priming ${ }^{159}$ of cytotoxic Tlymphocytes. However, some have noted that promising results in animal models may not translate to humans, as TLR9 expression across human immune cell types are more limited. ${ }^{160}$ Exciting for the field, the first vaccine with unconjugated $\mathrm{CpG}$ (Heplisav) was just approved for use in humans indicating the vast potential of this class of compounds.

Many studies report conjugates of $\mathrm{CpG}$ ODN linked through either the 3' or 5' end (Fig. 6B). However, the optimal orientation for $\mathrm{CpG}$ ODN in conjugates remains controversial. The crystal structure of extracellular domain of horse TLR9 ligated to $\mathrm{CpG}$ suggests that the 5 ' end may be more accessible for conjugation (Fig. 6B). It should be noted however that the 5 ' end is positioned at the bottom of the TLR9 complex, towards the endosomal membrane, which could inflict steric constraints on 5' end $\mathrm{CpG}$ conjugates. Crystal structure analysis has been insufficient to determine optimal binding sites as suggest by SAR studies. Initial reports by Agrawal and coworkers suggested that the 3 ' end was ideal for conjugation and that a free 5' end was essential for agonist potency. ${ }^{161}$ For example, $\mathrm{CpG}$ dimers that were conjugated 5'-to-5' were significantly less immunogenic than 3'-to-3' tethered $\mathrm{CpG}$ ODNs, measured by the in vitro induction of spleen lymphocyte proliferation and splenomegaly. ${ }^{161}$ In a follow-up study, this decrease in TLR9 potency for 5' conjugation was shown to be dependent on the size of the attached moiety and independent of cellular uptake. ${ }^{162}$ In vivo, 5 ' conjugation of CpG ODNs to a bulky amyloid- $\beta$ peptide antigen sharply decreased IL-12 induction, while 3 ' conjugates elicited strong IL-12 responses in $\mathrm{C} 57 \mathrm{BL} / 6$ mice. $^{163}$ 

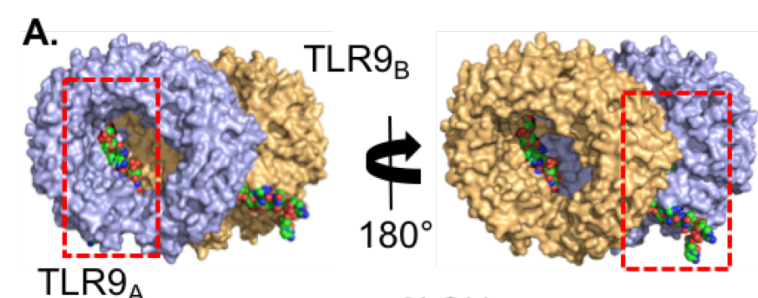

$\mathrm{TLR}_{\mathrm{A}}$

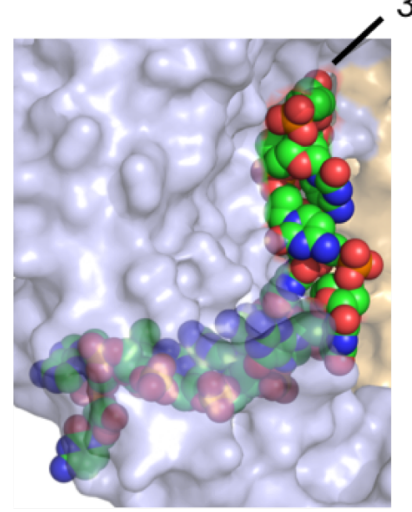

' $\mathrm{OH}$
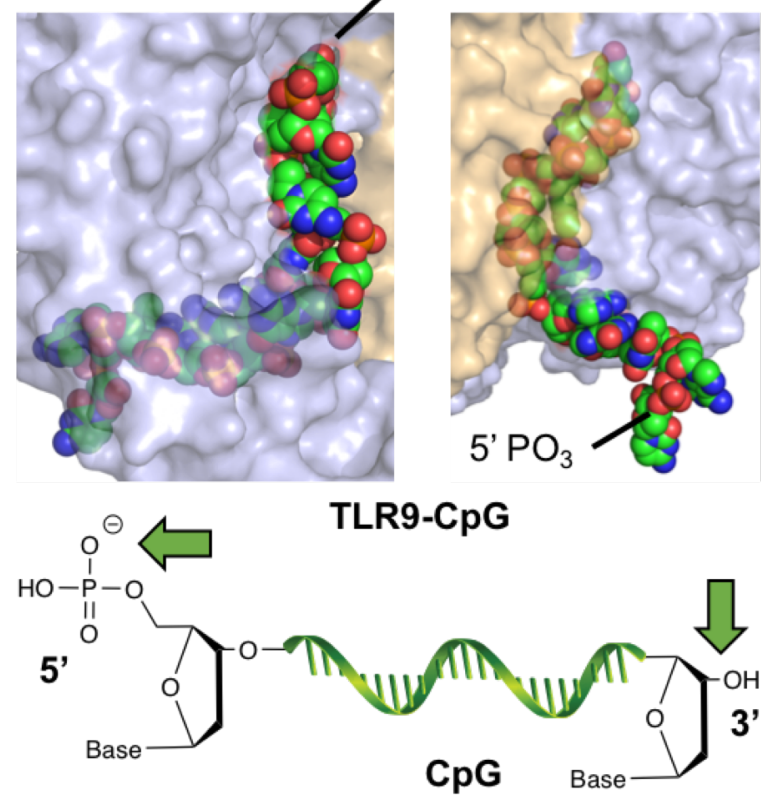

Figure 6. TLR9 agonists are ssDNAs that bind TLR9 dimers. (A) Two views of the horse TLR9-ssDNA (CpG 1668) crystal structure (PDB: 3WPC). Shown below each view is the zoomed region depicted by the red rectangle where TLR9 is shown at $40 \%$ transparency. The receptors bind to the $\mathrm{CpG}$ backbone and several nucleobases of the molecule. TLR9 shown in blue and orange, ssDNA shown in green. (B) Carton structure of $\mathrm{CpG}$. Green arrows highlight sites of conjugation.

However, some studies contradict the notion that 5, conjugation of $\mathrm{CpG}$ ODNs leads to reduced TLR9 potency compared to 3' conjugation. Zhang et al. showed that 5' conjugation of class B CpG ODN 1826 to bulky dextran polymers did not alter NF- $\kappa \mathrm{B}$ activity in TLR9-transfected HEK293 cells. ${ }^{12}$ It is however important to note that an acid labile imine bond ${ }^{164}$ was used to conjugate $\mathrm{CpG}$ to dextran in this study, which could facilitate release of $\mathrm{CpG}$ after endosomal uptake. Acid hydrolysis of the imine bond would free the 5 '-end of $\mathrm{CpG}$ and allow unobstructed binding to TLR9, which would explain why CpG conjugated to dextran retained TLR9 potency. We have however also observed (2fold) decreased TLR9 activity upon 3' CpG conjugation via thiol-maleimide chemistry with a triazine linker, while activity was maintained when conjugated through the 5' end (unpublished data). In an effort to end the controversy, Kramer et al. recently compared conjugation of CpG ODN 1668 to an ovalbumin (OVA) protein antigen through both 3' and 5' ends using an acid-stable bis-aryl hydrazone linker (Solulink Inc.). ${ }^{165}$ Interestingly, no statistically significant difference was found in the induction of proliferation of $\mathrm{CD}^{+}$and $\mathrm{CD} 8^{+} \mathrm{T}$ - cells and IFN- $\gamma$ production in T-cells from OT-I and OT-II mice between the 3 ' and 5' CpG-OVA conjugates. ${ }^{165}$ This study suggests that both 3' and 5' conjugation of CpG ODNs yield conjugates with comparable potency for induction of cellular T-cell responses, and therefore, that in some cases 5 ' conjugation does not lead to reduced TLR9 potency of $\mathrm{CpG}$.

Conjugation of $\mathrm{CpG}$ ODNs is easily achieved by synthesizing, or ordering, custom $\mathrm{CpG}$ ODNs containing reactive groups on the $3^{\prime}$ or $5^{\prime}$ termini via automated phosphoramidite DNA synthesis. In terms of structural requirements for $\mathrm{CpG} \mathrm{ODN}$ conjugation, both 3' and 5' conjugation of $\mathrm{CpG}$ ODNs can yield functional conjugates, albeit with reduced potency for some reported 5' conjugates. Recent studies show that $5^{\prime}$ conjugation of $\mathrm{CpG}$ does not necessarily lead to decreased potency, although other studies suggest that a free 5' end of $\mathrm{CpG}$ is vital for immune stimulation. Thus, either $3^{\prime}$ or 5' linkage strategies are appropriate for most conjugates. However, TLR9 activity of conjugates should be confirmed prior to application.

\section{- Conclusions}

TLR agonists have demonstrated their therapeutic potential in a variety of applications, including approved vaccine adjuvants and cancer immunotherapies. However, off-target effects, like systemic inflammation, have limited their practicality in the clinic. Covalent conjugation of TLR agonists to other functional compounds can circumvent these issues by generating effective, directed immune responses. Although only one TLR-agonist conjugate, Trumenba, has been FDA approved, these compounds have shown immense promise and additional studies will advance their implementation.

Production of TLR-conjugates requires careful design to ensure efficacy. Through case studies with SAR analysis, TLRagonist crystal structure evaluation, and molecular modeling, we have learned important considerations when designing TLR agonist conjugates. These considerations include the choice of agonists, choice of linkage chemistry, slection of conjugation sites that maintain agonist activity, and scalability considerations. TLR agonist discovery and chemical insights in effective TLR agonist conjugation will accelerate the ongoing developments at the forefront of vaccine and immunotherapy development.

\section{AUTHOR INFORMATION}

\section{Corresponding Author}

*Email: aesserkahn@uchicago.edu;

Martijn.Verdoes@Radboudumc.nl

\section{ORCID}

Martijn Verdoes: 0000-0001-8753-3528

Aaron Esser-Kahn: 0000-0003-1273-0951

\section{Author Contributions}

The manuscript was written through contributions of all authors. All authors have given approval to the final version of the manuscript. "These authors contributed equally.

\section{Notes}

The authors declare no competing financial interest.

\section{ACKNOWLEDGMENT}

This work was supported by grants (7DP2A1112194-02), (5U01AI124286-02), and, in part, by the Alfred P. Sloan, the Pew 
Charitable Trust, and the Cottrell Scholars Program. M.V. is a recipient of ERC Starting Grant CHEMCHECK (679921) and a Gravity Program Institute for Chemical Immunology Tenure Track Grant by NWO.

\section{ABBREVIATIONS}

TLR, toll-like receptor; PRR, pattern recognition receptor; PAMP, pathogen-associated molecular pattern; DAMP, damage-associated molecular pattern; dsRNA, double-stranded RNA; ssRNA, single stranded RNA; CpG, cytosine-phosphate-guanosine; APC, antigen presenting cell; DC, dendritic cell; LTA, lipoteichoic acid; ODN, oligodeoxynucleotides; LLC, Lewis lung carcinoma; NHS, Nhydroxysuccinimide; SPPS, solid phase peptide synthesis; TACA, tumor associated carbohydrate antigen; NCL, native chemical ligation; SAR, structure activity relationship; HPV, human papillomavirus; poly(I:C), polyinosinic-polycytidylic acid; OVA, ovalbumin; cDC, conventional DC; MD2, myeloid differentiation factor 2; LPS, lipopolysaccharide; MPLA, monophosphoryl lipid A; GLA, glucopyranosyl lipid adjuvant; SLA, second-generation lipid adjuvant; CDI, carbonyldiimidazole; NIPAM, Nisopropylacrylamide; NVOC, nitroveratryloxycarbonyl: NPPOC, 2-(2-nitrophenyl)propyl chloroformate; SMIP, small molecule immunopotentiators; CuAAC, copper(I)-catalyzed alkyne-azide cycloaddition.

\section{REFERENCES}

(1) Kawai, T., and Akira, S. (2010) The role of pattern-recognition receptors in innate immunity: update on Toll-like receptors. Nat. Immunol. $11,373-384$.

(2) Baldridge, J. R., McGowan, P., Evans, J. T., Cluff, C., Mossman, S., Johnson, D., and Persing, D. (2004) Taking a Toll on human disease: Tolllike receptor 4 agonists as vaccine adjuvants and monotherapeutic agents. Expert Opin. Biol. Ther. 4, 1129-1138.

(3) Schön, M. P., and Schön, M. (2008) TLR7 and TLR8 as targets in cancer therapy. Nature 27, 190-199.

(4) Marshak-Rothstein, A. (2006) Toll-like receptors in systemic autoimmune disease. Nat. Rev. Immunol. 6, 823 .

(5) Kanzler, H., Barrat, F. J., Hessel, E. M., and Coffman, R. L. (2007) Therapeutic targeting of innate immunity with Toll-like receptor agonists and antagonists. Nat. Med. 13, 552-559.

(6) Steinhagen, F., Kinjo, T., Bode, C., and Klinman, D. M. (2011) TLRbased immune adjuvants. Vaccine 29, 3341-3355.

(7) Lampkin, B. C., Levine, A. S., Levy, H., Krivit, W., and Hammond, D. (1985) Phase II Trial of a Complex Polyriboinosinic-Polyribocytidylic Acid with Poly-L-lysine and Carboxymethyl Cellulose in the Treatment of Children with Acute Leukemia and Neuroblastoma: A Report from the Children's Cancer Study Group. Cancer Res. 45, 5904 LP-5909.

(8) Pockros, P. J., Guyader, D., Patton, H., Tong, M. J., Wright, T., McHutchison, J. G., and Meng, T.-C. (2007) Oral resiquimod in chronic $\mathrm{HCV}$ infection: Safety and efficacy in 2 placebo-controlled, double-blind phase IIa studies. J. Hepatol. 47, 174-182.

(9) Robinson, R. A., DeVita, V. T., Levy, H. B., Baron, S., Hubbard, S. P., and Levine, A. S. (1976) A phase I-II trial of multiple-dose polyriboinosic-polyribocytidylic acid in patieonts with leukemia or solid tumors. J. Natl. Cancer Inst. 57, 599-602.

(10) Fujita, Y., and Taguchi, H. (2012) Overview and outlook of Tolllike receptor ligand-antigen conjugate vaccines. Ther. Deliv. 3, 749-760.

(11) Blander, J. M., and Medzhitov, R. (2006) Toll-dependent selection of microbial antigens for presentation by dendritic cells. Nature 440, 808 .

(12) Zhang, W., An, M., Xi, J., and Liu, H. (2017) Targeting CpG Adjuvant to Lymph Node via Dextran Conjugate Enhances Antitumor Immunotherapy. Bioconjug. Chem. 28, 1993-2000.

(13) Lynn, G. M., Laga, R., Darrah, P. A., Ishizuka, A. S., Balaci, A. J., Dulcey, A. E., Pechar, M., Pola, R., Gerner, M. Y., and Yamamoto, A. (2015) In vivo characterization of the physicochemical properties of polymer-linked TLR agonists that enhance vaccine immunogenicity. Nat. Biotechnol. 33, 1201-1210.

(14) Chan, M., Hayashi, T., Mathewson, R. D., Yao, S., Gray, C., Tawatao, R. I., Kalenian, K., Zhang, Y., Hayashi, Y., Lao, F. S., Cottam, H. B., and Carson, D. A. (2011) Synthesis and Characterization of PEGylated Toll Like Receptor 7 Ligands. Bioconjug. Chem. 22, 445-454.

(15) de Titta, A., Ballester, M., Julier, Z., Nembrini, C., Jeanbart, L., van der Vlies, A. J., Swartz, M. A., and Hubbell, J. A. (2013) Nanoparticle conjugation of $\mathrm{CpG}$ enhances adjuvancy for cellular immunity and memory recall at low dose. Proc. Natl. Acad. Sci. 110, 19902-19907.

(16) Lin, A. Y., Mattos Almeida, J. P., Bear, A., Liu, N., Luo, L., Foster, A. E., and Drezek, R. A. (2013) Gold Nanoparticle Delivery of Modified CpG Stimulates Macrophages and Inhibits Tumor Growth for Enhanced Immunotherapy. PLoS One 8, e63550.

(17) Wei, M., Chen, N., Li, J., Yin, M., Liang, L., He, Y., Song, H., Fan, C., and Huang, Q. (2012) Polyvalent Immunostimulatory Nanoagents with Self-Assembled CpG Oligonucleotide-Conjugated Gold Nanoparticles. Angew. Chemie Int. Ed. 51, 1202-1206.

(18) Chan, M., Hayashi, T., Kuy, C. S., Gray, C. S., Wu, C. C. N., Corr, M., Wrasidlo, W., Cottam, H. B., and Carson, D. A. (2009) Synthesis and immunological characterization of toll-like receptor 7 agonistic conjugates. Bioconjug. Chem. 20, 1194-1200.

(19) Andrews, C. D., Provoda, C. J., Ott, G., and Lee, K.-D. (2011) Conjugation of lipid and $\mathrm{CpG}$-containing oligonucleotide yields an efficient method for liposome incorporation. Bioconjug. Chem. 22, 1279-1286.

(20) Yu, C., An, M., Li, M., and Liu, H. (2017) Immunostimulatory Properties of Lipid Modified CpG Oligonucleotides. Mol. Pharm. 14, $2815-2823$.

(21) O'Neill, L. A. J., Golenbock, D., and Bowie, A. G. (2013) The history of Toll-like receptors -redefining innate immunity. Nat Rev Immunol 13, 453-460.

(22) Iwasaki, A., and Medzhitov, R. (2015) Control of adaptive immunity by the innate immune system. Nat. Immunol. 16, 343 .

(23) Iwasaki, A., and Medzhitov, R. (2004) Toll-like receptor control of the adaptive immune responses. Nat Immunol 5, 987-995.

(24) Barton, G. M., and Kagan, J. C. (2009) A cell biological view of Toll-like receptor function: regulation through compartmentalization. Nat. Rev. Immunol. 9, 535

(25) Medzhitov, R. (2001) Toll-like receptors and innate immunity. Nat. Rev. Immunol. 1, 135

(26) Oosting, M., Cheng, S.-C., Bolscher, J. M., Vestering-Stenger, R., Plantinga, T. S., Verschueren, I. C., Arts, P., Garritsen, A., van Eenennaam, H., Sturm, P., Kullberg, B.-J., Hoischen, A., Adema, G. J., van der Meer, J. W. M., Netea, M. G., and Joosten, L. A. B. (2014) Human TLR10 is an antiinflammatory pattern-recognition receptor. Proc. Natl. Acad. Sci. U. S. A. $111, \mathrm{E} 4478--84$.

(27) Jiang, S., Li, X., Hess, N. J., Guan, Y., and Tapping, R. I. (2016) TLR10 is a Negative Regulator of Both MyD88-Dependent and Independent TLR Signaling. J. Immunol. 196, 3834-3841.

(28) Hess, N. J., Felicelli, C., Grage, J., and Tapping, R. I. (2017) TLR10 suppresses the activation and differentiation of monocytes with effects on DC-mediated adaptive immune responses. J. Leukoc. Biol. 101, 1245-1252.

(29) Yamamoto, M., Sato, S., Hemmi, H., Hoshino, K., Kaisho, T., Sanjo, H., Takeuchi, O., Sugiyama, M., Okabe, M., Takeda, K., and Akira, S. (2003) Role of Adaptor TRIF in the MyD88-Independent Toll-Like Receptor Signaling Pathway. Science 301, 640-643.

(30) Akira, S., and Takeda, K. (2004) Toll-like receptor signalling. Nat. Rev. Immunol. 4, 499-511.

(31) $\mathrm{Wu}$, T. Y.-H. (2016) Strategies for designing synthetic immune agonists. Immunology 148, 315-325.

(32) $\mathrm{Xu}, \quad \mathrm{Z}$., and Moyle, P. M. 10.1021/acs.bioconjchem.7b00478. Bioconjug. Chem. In Press.

(33) Wu, T. Y.-H., Singh, M., Miller, A. T., De Gregorio, E., Doro, F., D’Oro, U., Skibinski, D. A. G., Mbow, M. L., Bufali, S., Herman, A. E., Cortez, A., Li, Y., Nayak, B. P., Tritto, E., Filippi, C. M., Otten, G. R., Brito, L. A., Monaci, E., Li, C., Aprea, S., Valentini, S., Calabró, S., Laera, D., Brunelli, B., Caproni, E., Malyala, P., Panchal, R. G., Warren, T. K., Bavari, S., O'Hagan, D. T., Cooke, M. P., and Valiante, N. M. (2014) Rational design of small molecules as vaccine adjuvants. Sci. Transl. Med. 6, 263 ra160.

(34) Oosenbrug, T., van de Graaff, M. J., Ressing, M. E., and van Kasteren, S. I. (2017) Chemical Tools for Studying TLR Signaling Dynamics. Cell Chem. Biol. 24, 801-812.

(35) Akira, S., Uematsu, S., and Takeuchi, O. (2006) Pathogen Recognition and Innate Immunity. Cell 124, 783-801.

(36) Jin, M. S., Kim, S. E., Heo, J. Y., Lee, M. E., Kim, H. M., Paik, S.G., Lee, H., and Lee, J.-O. (2007) Crystal Structure of the TLR1-TLR2 Heterodimer Induced by Binding of a Tri-Acylated Lipopeptide. Cell 130, 1071-1082.

(37) Spohn, R., Buwitt-Beckmann, U., Brock, R., Jung, G., Ulmer, A. J., and Wiesmüller, K.-H. (2004) Synthetic lipopeptide adjuvants and Toll-like receptor 2-structure-activity relationships. Vaccine 22, 2494-2499.

(38) Omueti, K. O., Beyer, J. M., Johnson, C. M., Lyle, E. A., and 
Tapping, R. I. (2005) Domain Exchange between Human Toll-like Receptors 1 and 6 Reveals a Region Required for Lipopeptide Discrimination. J. Biol. Chem. 280, 36616-36625.

(39) Khan, S., Weterings, J. J., Britten, C. M., de Jong, A. R., Graafland, D., Melief, C. J. M., van der Burg, S. H., van der Marel, G., Overkleeft, H. S., Filippov, D. V, and Ossendorp, F. (2009) Chirality of TLR-2 ligand Pam3CysSK4 in fully synthetic peptide conjugates critically influences the induction of specific CD8+ T-cells. Mol. Immunol. 46, 1084-1091.

(40) Zaman, M., and Toth, I. (2013) Immunostimulation by Synthetic Lipopeptide-Based Vaccine Candidates: Structure-Activity Relationships. Front. Immunol. 4, 318.

(41) Jung, G., Wiesmüller, K.-H., Becker, G., Bühring, H.-J., and Bessler, W. G. (1985) Increased Production of Specific Antibodies by Presentation of the Antigen Determinants with Covalently Coupled Lipopetide Mitogens. Angew. Chemie Int. Ed. 24, 872-873.

(42) Schwandner, R., Dziarski, R., Wesche, H., Rothe, M., and Kirschning, C. J. (1999) Peptidoglycan- and Lipoteichoic Acid-induced Cell Activation Is Mediated by Toll-like Receptor 2. J. Biol. Chem. 274, 17406-17409.

(43) Ryu, K. A., Slowinska, K., Moore, T., and Esser-Kahn, A. Immune Response Modulation of Conjugated Agonists with Changing Linker Length. ACS Chem. Biol. 11, 3347-3352.

(44) Mancini, R. J., Tom, J. K., and Esser-Kahn, A. P. (2014) Covalently Coupled Immunostimulant Heterodimers. Angew. Chemie Int. Ed. 53, 189 192.

(45) Tom, J. K., Mancini, R. J., and Esser-Kahn, A. P. (2013) Covalent modification of cell surfaces with TLR agonists improves \& directs immune stimulation. Chem. Commun. 49, 9618-9620.

(46) Luo, Y., Friese, O. V, Runnels, H. A., Khandke, L., Zlotnick, G., Aulabaugh, A., Gore, T., Vidunas, E., Raso, S. W., Novikova, E., Byrne, E., Schlittler, M., Stano, D., Dufield, R. L., Kumar, S., Anderson, A. S. Jansen, K. U., and Rouse, J. C. (2016) The Dual Role of Lipids of the Lipoproteins in Trumenba, a Self-Adjuvanting Vaccine Against Meningococcal Meningitis B Disease. AAPS J. 18, 1562-1575.

(47) Fletcher, L. D., Bernfield, L., Barniak, V., Farley, J. E., Howell, A., Knauf, M., Ooi, P., Smith, R. P., Weise, P., Wetherell, M., Xie, X., Zagursky, R., Zhang, Y., and Zlotnick, G. W. (2004) Vaccine Potential of the Neisseria meningitidis 2086 Lipoprotein. Infect. Immun. 72, 2088-2100.

(48) Khan, S., Bijker, M. S., Weterings, J. J., Tanke, H. J., Adema, G. J., van Hall, T., Drijfhout, J. W., Melief, C. J. M., Overkleeft, H. S., and van der Marel, G. A. (2007) Distinct uptake mechanisms but similar intracellular processing of two different toll-like receptor ligand-peptide conjugates in dendritic cells. J. Biol. Chem. 282, 21145-21159.

(49) Ingale, S., Wolfert, M. A., Gaekwad, J., Buskas, T., and Boons, G.J. (2007) Robust immune responses elicited by a fully synthetic threecomponent vaccine. Nat. Chem. Biol. 3, 663.

(50) Zom, G. G., Khan, S., Britten, C. M., Sommandas, V., Camps, M. G. M., Loof, N. M., Budden, C. F., Meeuwenoord, N. J., Filippov, D. V, and Marel, G. A. Van Der. (2014) Efficient Induction of Antitumor Immunity by Synthetic Toll-like Receptor Ligand - Peptide Conjugates. Cancer Immunol. Res. 2, 756-765.

(51) Zeng, W., Ghosh, S., Lau, Y. F., Brown, L. E., and Jackson, D. C. (2002) Highly Immunogenic and Totally Synthetic Lipopeptides as SelfAdjuvanting Immunocontraceptive Vaccines. J. Immunol. 169, 4905-4912.

(52) Ingale, S., Buskas, T., and Boons, G.-J. (2006) Synthesis of Glyco(lipo)peptides by Liposome-Mediated Native Chemical Ligation. Org. Lett. 8, 5785-5788.

(53) Nalla, N., Pallavi, P., Srinivasa, B., Miryala, S., Kumar, V. N., Mahboob, M., and Sampath, H. M. (2015) Bioorganic \& Medicinal Chemistry Design, synthesis and immunological evaluation of $1,2,3-$ triazole- tethered carbohydrate - Pam 3 Cys conjugates as TLR2 agonists. Bioorg. Med. Chem. 23, 5846-5855.

(54) Cai, H., Huang, Z., Shi, L., Zhao, Y., Kunz, H., and Li, Y. (2011) Towards a Fully Synthetic MUC1-Based Anticancer Vaccine: Efficient Conjugation of Glycopeptides with Mono-, Di-, and Tetravalent Lipopeptides Using Click Chemistry. Chem. - A Eur. J. 17, 6396-6406.

(55) Cai, H., Sun, Z., Huang, Z., Shi, L., Zhao, Y., Kunz, H., and Li, Y. (2013) Fully Synthetic Self-Adjuvanting Thioether-Conjugated Glycopeptide- Lipopeptide Antitumor Vaccines for the Induction of Complement-Dependent Cytotoxicity against Tumor Cells. Chem. Eur. J. 19, 1962-1970.

(56) Wilkinson, B. L., Malins, L. R., Chun, C. K. Y., and Payne, R. J. (2010) Synthesis of MUC1-lipopeptide chimeras. Chem. Commun. (Camb). $46,6249-6251$.

(57) Wilkinson, B. L., Day, S., Malins, L. R., Apostolopoulos, V., and Payne, R. J. (2011) Self-Adjuvanting Multicomponent Cancer Vaccine
Candidates Combining Per-Glycosylated MUC1 Glycopeptides and the Toll-like Receptor 2 Agonist Pam3CysSer. Angew. Chemie 123, 16731677.

(58) Metzger, J. W., Beck-Sickinger, A. G., Loeit, M., Eckert, M., Bessler, W. G., and Jung, G. (1995) Synthetic S-(2, 3-dihydroxypropyl)cysteinyl peptides derived from the N-terminus of the cytochrome subunit of the photoreaction centre of Rhodopseudomonas viridis enhance murine splenocyte proliferation. J. Pept. Sci. 1, 184-190.

(59) Muhlradt, P. F., Kiess, M., Meyer, H., Sussmuth, R., and Jung, G. (1998) Structure and specific activity of macrophage-stimulating lipopeptides from Mycoplasma hyorhinis. Infect. Immun. 66, 4804-4810.

(60) Huynh, A. S., Chung, W. J., Cho, H.-I., Moberg, V. E., Celis, E., Morse, D. L., and Vagner, J. (2012) Novel toll-like receptor 2 ligands for targeted pancreatic cancer imaging and immunotherapy. J. Med. Chem. 55, 9751-9762.

(61) Mancini, R. J., Stutts, L., Moore, T., and Esser-Kahn, A. P. (2015) Controlling the origins of inflammation with a photoactive lipopeptide immunopotentiator. Angew. Chemie 127, 6060-6063.

(62) McDonald, D. M., Wilkinson, B. L., Corcilius, L., ThaysenAndersen, M., Byrne, S. N., and Payne, R. J. (2014) Synthesis and immunological evaluation of self-adjuvanting MUC1-macrophage activating lipopeptide 2 conjugate vaccine candidates. Chem. Commun. 50 , 10273-10276.

(63) Willems, M. M. J. H. P., Zom, G. G., Khan, S., Meeuwenoord, N., Melief, C. J. M., van der Stelt, M., Overkleeft, H. S., Codée, J. D. C., van der Marel, G. A., Ossendorp, F., and Filippov, D. V. (2014) NTetradecylcarbamyl Lipopeptides as Novel Agonists for Toll-like Receptor 2. J. Med. Chem. 57, 6873-6878.

(64) Zom, G. G., Welters, M. J. P., Loof, N. M., Goedemans, R., Lougheed, S., Valentijn, R. R. P. M., Zandvliet, M. L., Meeuwenoord, N. J., Melief, C. J. M., de Gruijl, T. D., Van der Marel, G. A., Filippov, D. V, Ossendorp, F., and Van der Burg, S. H. (2016) TLR2 ligand-synthetic long peptide conjugates effectively stimulate tumor-draining lymph node T cells of cervical cancer patients. Oncotarget 7, 67087-67100.

(65) Guo, X., Wu, N., Shang, Y., Liu, X., Wu, T., Zhou, Y., Liu, X., Huang, J., Liao, X., and Wu, L. (2017) The Novel Toll-Like Receptor 2 Agonist SUP3 Enhances Antigen Presentation and T Cell Activation by Dendritic Cells. Front. Immunol. 8, 158.

(66) Salunke, D. B., Shukla, N. M., Yoo, E., Crall, B. M., Balakrishna, R., Malladi, S. S., and David, S. A. (2012) Structure-Activity Relationships in Human Toll-like Receptor 2-Specific Monoacyl Lipopeptides. J. Med. Chem. 55, 3353-3363.

(67) Hamley, I. W., Kirkham, S., Dehsorkhi, A., Castelletto, V., Reza, M., and Ruokolainen, J. (2014) Toll-like receptor agonist lipopeptides selfassemble into distinct nanostructures. Chem. Commun. 50, 15948-15951.

(68) Al-isae, K., Zaman, M., and Toth, I. (2011) Simple synthetic tolllike receptor 2 ligands. Bioorg. Med. Chem. Lett. 21, 5863-5865.

(69) Zaman, M., Abdel-Aal, A.-B. M., Phillipps, K. S. M., Fujita, Y., Good, M. F., and Toth, I. (2010) Structure-activity relationship of lipopeptide Group A streptococcus (GAS) vaccine candidates on toll-like receptor 2. Vaccine 28, 2243-2248.

(70) Guan, Y., Omueti-Ayoade, K., Mutha, S. K., Hergenrother, P. J., and Tapping, R. I. (2010) Identification of novel synthetic toll-like receptor 2 agonists by high throughput screening. J. Biol. Chem. 285, 23755-23762.

(71) Jensen, S., and Thomsen, A. R. (2012) Sensing of RNA Viruses: a Review of Innate Immune Receptors Involved in Recognizing RNA Virus Invasion. J. Virol. 86, 2900-2910.

(72) Alexopoulou, L., Holt, A. C., Medzhitov, R., and Flavell, R. A. (2001) Recognition of double-stranded RNA and activation of NF-KB by Toll-like receptor 3. Nature 413, 732.

(73) Lauterbach, H., Bathke, B., Gilles, S., Traidl-Hoffmann, C., Luber, C. A., Fejer, G., Freudenberg, M. A., Davey, G. M., Vremec, D., Kallies, A., Wu, L., Shortman, K., Chaplin, P., Suter, M., OltextquoterightKeeffe, M., and Hochrein, H. (2010) Mouse CD8 $\alpha+$ DCs and human BDCA3+ DCs are major producers of IFN- $\lambda$ in response to poly IC. J. Exp. Med. 207, 2703-2712.

(74) Gitlin, L., Barchet, W., Gilfillan, S., Cella, M., Beutler, B., Flavell, R. A., Diamond, M. S., and Colonna, M. (2006) Essential role of mda-5 in type I IFN responses to polyriboinosinic: polyribocytidylic acid and encephalomyocarditis picornavirus. Proc. Natl. Acad. Sci. 103, 8459-8464.

(75) Wang, X., Smith, C., Yin, H., Wang, X., Smith, C., and Yin, H. (2013) Targeting Toll-like receptors with small molecule agents. Chem. Soc. Rev. 42, 4859-4866.

(76) Brodsky, I., Strayer, D. R., Krueger, L. J., and Carter, W. A. (1985) Clinical studies with ampligen (mismatched double-stranded RNA). J. Biol. Response Mod. 4, 669-675. 
(77) Andres, M. S., Hilton, B. L., Steven, O., Meir, K., Barbara, S., Douglas, B., Hernando, M., Norman, M., Karen, S., Daniel, D., David, D., Morris, P., Mark, I., Maria, G., Herbert, B., and Alex, O. (1996) Long-term Treatment of Malignant Gliomas with Intramuscularly Administered Polyinosinic-Polycytidylic Acid Stabilized with Polylysine and Carboxymethylcellulose: An Open Pilot Study. Neurosurgery 38, 10961104.

(78) Huang, Q., Yu, W., and Hu, T. (2016) Potent Antigen-Adjuvant Delivery System by Conjugation of Mycobacterium tuberculosis Ag85BHspX Fusion Protein with Arabinogalactan-Poly (I: C) Conjugate. Bioconjug. Chem. 27, 1165-1174.

(79) Liu, L., Botos, I., Wang, Y., Leonard, J. N., Shiloach, J., Segal, D. M., and Davies, D. R. (2008) Structural Basis of Toll-Like Receptor 3 Signaling with Double-Stranded RNA. Science 320, 379-381.

(80) Chu, B. C. F., Wahl, G. M., and Orgel, L. E. (1983) Derivatization of unprotected polynucleotides. Nucleic Acids Res. 11, 6513-6529.

(81) Lund, V., Schmid, R., Rickwood, D., Robbiati, F., and Homes, E. (1988) Assessment of methods for covalent binding of nucleic acids to magnetic beads, Dynabeads TM, and the characteristics of the bound nucleic acids in hybridization reactions . Nucleic Acids Res. 16, 1086110880

(82) Shukoor, M. I., Natalio, F., Metz, N., Glube, N., Tahir, M. N., Therese, H. A., Ksenofontov, V., Theato, P., Langguth, P., Boissel, J.-P., Schröder, H. C., Müller, W. E. G., and Tremel, W. (2008) dsRNAFunctionalized Multifunctional $\gamma$-Fe2O3 Nanocrystals: A Tool for Targeting Cell Surface Receptors. Angew. Chemie Int. Ed. 47, 4748-4752.

(83) Shukoor, M. I., Natalio, F., Ksenofontov, V., Tahir, M. N., Eberhardt, M., Theato, P., Schröder, H. C., Müller, W. E. G., and Tremel, W. (2007) Double-Stranded RNA Polyinosinic-Polycytidylic Acid Immobilized onto $\gamma$-Fe2O3 Nanoparticles by Using a Multifunctional Polymeric Linker. Small 3, 1374-1378.

(84) Zhang, L., Dewan, V., and Yin, H. (2017) Discovery of Small Molecules as Multi-Toll-like Receptor Agonists with Proinflammatory and Anticancer Activities. J. Med. Chem. 60, 5029-5044.

(85) Zhang, P., Chiu, Y.-C., Tostanoski, L. H., and Jewell, C. M. (2015) Polyelectrolyte Multilayers Assembled Entirely from Immune Signals on Gold Nanoparticle Templates Promote Antigen-Specific T Cell Response. ACS Nano 9, 6465-6477.

(86) Chiu, Y.-C., Gammon, J. M., Andorko, J. I., Tostanoski, L. H., and Jewell, C. M. (2015) Modular Vaccine Design Using Carrier-Free Capsules Assembled from Polyionic Immune Signals. ACS Biomater. Sci. Eng. 1, 1200-1205.

(87) Chiu, Y.-C., Gammon, J. M., Andorko, J. I., Tostanoski, L. H., and Jewell, C. M. (2016) Assembly and Immunological Processing of Polyelectrolyte Multilayers Composed of Antigens and Adjuvants. ACS Appl. Mater. Interfaces 8, 18722-18731.

(88) Poltorak, A., He, X., Smirnova, I., Liu, M.-Y., Huffel, C. Van, Du, X., Birdwell, D., Alejos, E., Silva, M., Galanos, C., Freudenberg, M., Ricciardi-Castagnoli, P., Layton, B., and Beutler, B. (1998) Defective LPS Signaling in $\mathrm{C} 3 \mathrm{H} / \mathrm{HeJ}$ and $\mathrm{C} 57 \mathrm{BL} / 10 \mathrm{ScCr}$ Mice: Mutations in Tlr4 Gene. Science 282, 2085-2088.

(89) Hoshino, K., Takeuchi, O., Kawai, T., Sanjo, H., Ogawa, T., Takeda, Y., Takeda, K., and Akira, S. (1999) Cutting Edge: Toll-Like Receptor 4 (TLR4)-Deficient Mice Are Hyporesponsive to Lipopolysaccharide: Evidence for TLR4 as the LPS Gene Product. $J$ Immunol. 162, 3749-3752.

(90) Park, B. S., Song, D. H., Kim, H. M., Choi, B.-S., Lee, H., and Lee, J.-O. (2009) The structural basis of lipopolysaccharide recognition by the TLR4-MD-2 complex. Nature 458, 1191-1195.

(91) Shen, H., Tesar, B. M., Walker, W. E., and Goldstein, D. R. (2008) Dual Signaling of MyD88 and TRIF Is Critical for Maximal TLR4-Induced Dendritic Cell Maturation. J. Immunol. 181, 1849 LP-1858.

(92) Carter, D., Fox, C. B., Day, T. A., Guderian, J. A., Liang, H., Rolf, T., Vergara, J., Sagawa, Z. K., Ireton, G., Orr, M. T., Desbien, A., Duthie, M. S., Coler, R. N., and Reed, S. G. (2016) A structure-function approach to optimizing TLR4 ligands for human vaccines. Clin Trans Immunol. 5, e108.

(93) Qureshi, N., Takayama, K., and Ribi, E. (1982) Purification and structural determination of nontoxic lipid A obtained from the lipopolysaccharide of Salmonella typhimurium. J. Biol. Chem. 257, 11808 11815

(94) Reed, S. G., Hsu, F.-C., Carter, D., and Orr, M. T. (2016) The science of vaccine adjuvants: advances in TLR4 ligand adjuvants. Curr. Opin. Immunol. 41, 85-90.

(95) Casella, C. R., and Mitchell, T. C. (2008) Putting endotoxin to work for us: Monophosphoryl lipid A as a safe and effective vaccine adjuvant
Cell. Mol. Life Sci. 65, 3231.

(96) Mata-Haro, V., Cekic, C., Martin, M., Chilton, P. M., Casella, C. R., and Mitchell, T. C. (2007) The Vaccine Adjuvant Monophosphoryl Lipid A as a TRIF-Biased Agonist of TLR4. Science 316, 1628-1632.

(97) Schülke, S., Vogel, L., Junker, A.-C., Hanschmann, K.-M., Flaczyk, A., Vieths, S., and Scheurer, S. (2016) A Fusion Protein Consisting of the Vaccine Adjuvant Monophosphoryl Lipid A and the Allergen Ovalbumin Boosts Allergen-Specific Th1, Th2, and Th17 Responses In Vitro. J. Immunol. Res.

(98) Zhou, Z., Mondal, M., Liao, G., and Guo, Z. (2014) Synthesis and evaluation of monophosphoryl lipid A derivatives as fully synthetic selfadjuvanting glycoconjugate cancer vaccine carriers. Org. Biomol. Chem. $12,3238-3245$.

(99) Zhou, Z., Liao, G., Mandal, S. S., Suryawanshi, S., and Guo, Z. (2015) A fully synthetic self-adjuvanting globo H-Based vaccine elicited strong T cell-mediated antitumor immunity. Chem. Sci. 6, 7112-7121.

(100) Wang, Q., Zhou, Z., Tang, S., and Guo, Z. (2012) CarbohydrateMonophosphoryl Lipid A Conjugates Are Fully Synthetic Self-Adjuvanting Cancer Vaccines Eliciting Robust Immune Responses in the Mouse. ACS Chem. Biol. 7, 235-240.

(101) Wang, L., Feng, S., Wang, S., Li, H., Guo, Z., and Gu, G. (2017) Synthesis and Immunological Comparison of Differently Linked Lipoarabinomannan Oligosaccharide-Monophosphoryl Lipid A Conjugates as Antituberculosis Vaccines. J. Org. Chem. 82, 12085-12096.

(102) Liao, G., Zhou, Z., Suryawanshi, S., Mondal, M. A., and Guo, Z. (2016) Fully Synthetic Self-Adjuvanting $\alpha-2,9-O$-Olgosialic Acid Based Conjugate Vaccines against Group C Meningitis. ACS Cent. Sci. 2, 210 218.

(103) Matyas, G. R., Mayorov, A. V, Rice, K. C., Jacobson, A. E., Cheng, K., Iyer, M. R., Li, F., Beck, Z., Janda, K. D., and Alving, C. R. (2013) Liposomes containing monophosphoryl lipid A: A potent adjuvant system for inducing antibodies to heroin hapten analogs. Vaccine 31, 2804 2810 .

(104) Weilhammer, D., Dunkle, A. D., Blanchette, C. D., Fischer, N. O., Corzett, M., Lehmann, D., Boone, T., Hoeprich, P., Driks, A., and Rasley, A. (2017) Enhancement of antigen-specific CD4+ and CD8+ T cell responses using a self-assembled biologic nanolipoprotein particle vaccine. Vaccine 35, 1475-1481

(105) Didierlaurent, A. M., Laupèze, B., Di Pasquale, A., Hergli, N. Collignon, C., and Garçon, N. (2017) Adjuvant system AS01: helping to overcome the challenges of modern vaccines. Expert Rev. Vaccines 16, 55 63

(106) Chan, M., Hayashi, T., Mathewson, R. D., Nour, A., Hayashi, Y., Yao, S., Tawatao, R. I., Crain, B., Tsigelny, I. F., and Kouznetsova, V. L. (2013) Identification of substituted pyrimido [5, 4-b] indoles as selective Toll-like receptor 4 ligands. J. Med. Chem. 56, 4206-4223.

(107) Tom, J. K., Dotsey, E. Y., Wong, H. Y., Stutts, L., Moore, T., Davies, D. H., Felgner, P. L., and Esser-Kahn, A. P. (2015) Modulation of Innate Immune Responses via Covalently Linked TLR Agonists. ACS Cent. Sci. 1, 439-448.

(108) Stutts, L., and Esser-Kahn, A. P. (2015) A Light-Controlled TLR4 Agonist and Selectable Activation of Cell Subpopulations. ChemBioChem 16, 1744-1748.

(109) Chan, M., Kakitsubata, Y., Hayashi, T., Ahmadi, A., Yao, S., Shukla, N. M., Oyama, S., Baba, A., Nguyen, B., Corr, M., Suda, Y., Carson, D. A., Cottam, H. B., and Wakao, M. (2017) Structure-Activity Relationship Studies of Pyrimido[5,4-b]indoles as Selective Toll-Like Receptor 4 Ligands. J. Med. Chem. 60, 9142-9161.

(110) Nour, A., Hayashi, T., Chan, M., Yao, S., Tawatao, R. I., Crain, B., Tsigelny, I. F., Kouznetsova, V. L., Ahmadiiveli, A., Messer, K., Pu, M., Corr, M., Carson, D. A., and Cottam, H. B. (2014) Discovery of substituted 4-aminoquinazolines as selective Toll-like receptor 4 ligands. Bioorg. Med. Chem. Lett. 24, 4931-4938.

(111) Wang, Y., Su, L., Morin, M. D., Jones, B. T., Whitby, L. R., Surakattula, M. M. R. P., Huang, H., Shi, H., Choi, J. H., Wang, K., Moresco, E. M. Y., Berger, M., Zhan, X., Zhang, H., Boger, D. L., and Beutler, B. (2016) TLR4/MD-2 activation by a synthetic agonist with no similarity to LPS. Proc. Natl. Acad. Sci. 113, E884-E893.

(112) Marshall, J. D., Heeke, D. S., Rao, E., Maynard, S. K., Hornigold, D., McCrae, C., Fraser, N., Tovchigrechko, A., Yu, L., Williams, N., King, S., Cooper, M. E., Hajjar, A. M., and Woo, J. C. (2016) A Novel Class of Small Molecule Agonists with Preference for Human over Mouse TLR4 Activation. PLoS One 11, e0164632.

(113) Neve, J. E., Wijesekera, H. P., Duffy, S., Jenkins, I. D., Ripper, J. A., Teague, S. J., Campitelli, M., Garavelas, A., Nikolakopoulos, G., Le, P. V, de A. Leone, P., Pham, N. B., Shelton, P., Fraser, N., Carroll, A. R., 
Avery, V. M., McCrae, C., Williams, N., and Quinn, R. J. (2014) Euodenine A: A Small-Molecule Agonist of Human TLR4. J. Med. Chem. 57, 12521275.

(114) Billod, J.-M., Lacetera, A., Guzmán-Caldentey, J., and MartínSantamaría, S. (2016) Computational Approaches to Toll-Like Receptor 4 Modulation. Mol. 21, E994.

(115) McDermott, P. F., Ciacci-Woolwine, F., Snipes, J. A., and Mizel, S. B. (2000) High-Affinity Interaction between Gram-Negative Flagellin and a Cell Surface Polypeptide Results in Human Monocyte Activation. Infect. Immun. 68, 5525-5529.

(116) Hayashi, F., Means, T. K., and Luster, A. D. (2003) Toll-like receptors stimulate human neutrophil function. Blood 102, 2660 LP-2669.

(117) Burdelya, L. G., Krivokrysenko, V. I., Tallant, T. C., Strom, E., Gleiberman, A. S., Gupta, D., Kurnasov, O. V, Fort, F. L., Osterman, A. L., DiDonato, J. A., Feinstein, E., and Gudkov, A. V. (2008) An Agonist of Toll-Like Receptor 5 Has Radioprotective Activity in Mouse and Primate Models. Science 320, 226-230.

(118) Guo, F., Liu, Y., Zhang, C., Wang, Q., Wang, L., Gao, Y., Bi, J., Wang, H., and Su, Z. (2017) Prompt and Robust Humoral Immunity Elicited by a Conjugated Chimeric Malaria Antigen with a Truncated Flagellin. Bioconjug. Chem. In Press.

(119) Mizel, S. B., and Bates, J. T. (2010) Flagellin as an Adjuvant: Cellular Mechanisms and Potential. J. Immunol. 185, 5677 LP-5682.

(120) Turley, C. B., Rupp, R. E., Johnson, C., Taylor, D. N., Wolfson, J., Tussey, L., Kavita, U., Stanberry, L., and Shaw, A. (2011) Safety and immunogenicity of a recombinant M2e-flagellin influenza vaccine (STF2.4xM2e) in healthy adults. Vaccine 29, 5145-5152.

(121) Tussey, L., Strout, C., Davis, M., Johnson, C., Lucksinger, G., Umlauf, S., Song, L., Liu, G., Abraham, K., and White, C. J. (2016) Phase 1 Safety and Immunogenicity Study of a Quadrivalent Seasonal Flu Vaccine Comprising Recombinant Hemagglutinin-Flagellin Fusion Proteins. Open Forum Infect. Dis. 3, ofw015-ofw015.

(122) Taylor, D. N., Treanor, J. J., Strout, C., Johnson, C., Fitzgerald, T., Kavita, U., Ozer, K., Tussey, L., and Shaw, A. (2011) Induction of a potent immune response in the elderly using the TLR-5 agonist, flagellin, with a recombinant hemagglutinin influenza-flagellin fusion vaccine (VAX125, STF2.HA1 SI). Vaccine 29, 4897-4902.

(123) Wang, L., Chang, T. Z., He, Y., Kim, J. R., Wang, S., Mohan, T. Berman, Z., Tompkins, S. M., Tripp, R. A., Compans, R. W., Champion, J. A., and Wang, B.-Z. (2017) Coated protein nanoclusters from influenza H7N9 HA are highly immunogenic and induce robust protective immunity. Nanomedicine Nanotechnology, Biol. Med. 13, 253-262.

(124) Salman, H. H., Irache, J. M., and Gamazo, C. (2009) Immunoadjuvant capacity of flagellin and mannosamine-coated poly(anhydride) nanoparticles in oral vaccination. Vaccine $27,4784-4790$.

(125) Z. Chang, T., Diambou, I., Kim, J., Wang, B.-Z., and Champion, J. (2016) Host- and Pathogen-Derived Adjuvant Coatings on Protein Nanoparticle Vaccines. Bioeng. Transl. Med.

(126) Simon, R., Wang, J. Y., Boyd, M. A., Tulapurkar, M. E., Ramachandran, G., Tennant, S. M., Pasetti, M., Galen, J. E., and Levine, M. M. (2013) Sustained protection in mice immunized with fractional doses of Salmonella enteritidis core and $\mathrm{O}$ polysaccharide-flagellin glycoconjugates. PLoS One 8, e64680.

(127) Andersen-Nissen, E., Smith, K. D., Bonneau, R., Strong, R. K., and Aderem, A. (2007) A conserved surface on Toll-like receptor 5 recognizes bacterial flagellin. J. Exp. Med. 204, 393 LP-403.

(128) Smith, K. D., Andersen-Nissen, E., Hayashi, F., Strobe, K. Bergman, M. A., Barrett, S. L. R., Cookson, B. T., and Aderem, A. (2003) Toll-like receptor 5 recognizes a conserved site on flagellin required for protofilament formation and bacterial motility. Nat. Immunol. 4, 12471253.

(129) González-Stegmaier, R., Guzmán, F., Albericio, F., VillarroelEspíndola, F., Romero, A., Mulero, V., and Mercado, L. (2015) A synthetic peptide derived from the D1 domain of flagellin induced the expression of proinflammatory cytokines in fish macrophages. Fish Shellfish Immunol. $47,239-244$.

(130) Heil, F., Hemmi, H., Hochrein, H., Ampenberger, F., Kirschning, C., Akira, S., Lipford, G., Wagner, H., and Bauer, S. (2004) SpeciesSpecific Recognition of Single-Stranded RNA via Toll-like Receptor 7 and 8. Science 303, 1526-1529.

(131) Kastenmüller, W., Kastenmüller, K., Kurts, C., and Seder, R. A (2014) Dendritic cell-targeted vaccines - hope or hype? Nat. Rev Immunol. 14, 705.

(132) Moyle, P. M., Dai, W., Zhang, Y., Batzloff, M. R., Good, M. F., and Toth, I. (2014) Site-Specific Incorporation of Three Toll-Like Receptor 2 Targeting Adjuvants into Semisynthetic, Molecularly Defined
Nanoparticles: Application to Group A Streptococcal Vaccines. Bioconjug. Chem. 25, 965-978.

(133) Larson, P., Kucaba, T. A., Xiong, Z., Olin, M., Griffith, T. S., and Ferguson, D. M. (2017) Design and Synthesis of N1-Modified Imidazoquinoline Agonists for Selective Activation of Toll-like Receptors 7 and 8. ACS Med. Chem. Lett. 8, 1148-1152.

(134) Gibbard, R. J., Morley, P. J., and Gay, N. J. (2006) Conserved features in the extracellular domain of human toll-like receptor 8 are essential for pH-dependent signaling. J. Biol. Chem. 281, 27503-27511.

(135) Kokatla, H. P., Yoo, E., Salunke, D. B., Sil, D., Ng, C. F., Balakrishna, R., Malladi, S. S., Fox, L. M., and David, S. A. (2013) Tolllike receptor-8 agonistic activities in $\mathrm{C} 2, \mathrm{C} 4$, and $\mathrm{C} 8$ modified thiazolo [4, 5-c] quinolines. Org. Biomol. Chem. 11, 1179-1198.

(136) Tyring, S., Conant, M., Marini, M., Van Der Meijden, W., and Washenik, K. (2002) Imiquimod; an international update on therapeutic uses in dermatology. Int. J. Dermatol. 41, 810-816.

(137) Savage, P., Horton, V., Moore, J., Owens, M., Witt, P., and Gore, M. E. (1996) A phase I clinical trial of imiquimod, an oral interferon inducer, administered daily. Br J Cancer 74, 1482-1486.

(138) Kurimoto, A., Ogino, T., Ichii, S., Isobe, Y., Tobe, M., Ogita, H. Takaku, H., Sajiki, H., Hirota, K., and Kawakami, H. (2004) Synthesis and evaluation of 2-substituted 8-hydroxyadenines as potent interferon inducers with improved oral bioavailabilities. Bioorg. Med. Chem. 12, 1091-1099.

(139) Wu, C. C. N., Hayashi, T., Takabayashi, K., Sabet, M., Smee, D F., Guiney, D. D., Cottam, H. B., and Carson, D. A. (2007) Immunotherapeutic activity of a conjugate of a Toll-like receptor 7 ligand. Proc. Natl. Acad. Sci. 104, 3990-3995.

(140) Weterings, J. J., Khan, S., van der Heden, G. J., Drijfhout, J. W. Melief, C. J. M., Overkleeft, H. S., van der Burg, S. H., Ossendorp, F., van der Marel, G. A., and Filippov, D. V. (2006) Synthesis of 2-alkoxy-8hydroxyadenylpeptides: Towards synthetic epitope-based vaccines. Bioorg. Med. Chem. Lett. 16, 3258-3261.

(141) Shukla, N. M., Mutz, C. A., Ukani, R., Warshakoon, H. J., Moore, D. S., and David, S. A. (2010) Syntheses of fluorescent imidazoquinoline conjugates as probes of Toll-like receptor 7. Bioorg. Med. Chem. Lett. 20, 6384-6386.

(142) Shukla, N. M., Lewis, T. C., Day, T. P., Mutz, C. A., Ukani, R., Hamilton, C. D., Balakrishna, R., and David, S. A. (2011) Toward selfadjuvanting subunit vaccines: Model peptide and protein antigens incorporating covalently bound toll-like receptor-7 agonistic imidazoquinolines. Bioorg. Med. Chem. Lett. 21, 3232-3236.

(143) Shukla, N. M., Mutz, C. A., Ukani, R., Warshakoon, H. J., Moore, D. S., and David, S. A. (2010) Bioorganic \& Medicinal Chemistry Letters Syntheses of fluorescent imidazoquinoline conjugates as probes of Toll-like receptor 7. Bioorg. Med. Chem. Lett. 20, 6384-6386.

(144) Shukla, N. M., Malladi, S. S., Mutz, C. A., Balakrishna, R., and David, A. (2011) Structure-Activity Relationships in Human Toll-like Receptor 7- Active Imidazoquinoline Analogues. J. Med. Chem 53, 4450 4465.

(145) Yoo, E., Crall, B. M., Balakrishna, R., Malladi, S. S., Fox, L. M., Hermanson, A. R., and David, S. A. (2013) Structure-activity relationships in Toll-like receptor 7 agonistic 1H-imidazo[4,5-c]pyridines. Org. Biomol. Chem. 11, 6526-6545.

(146) Tanji, H., Ohto, U., Shibata, T., Miyake, K., and Shimizu, T. (2013) Structural reorganization of the Toll-like receptor 8 dimer induced by agonistic ligands. Science 339, 1426-1429.

(147) Ryu, K. A., Stutts, L., Tom, J. K., Mancini, R. J., and Esser-Kahn, A. P. (2014) Stimulation of innate immune cells by light-activated TLR7/8 agonists. J. Am. Chem. Soc. 136, 10823-10825.

(148) Shukla, N. M., Mutz, C. A., Malladi, S. S., Warshakoon, H. J., Balakrishna, R., and David, S. A. (2012) Toll-like receptor (TLR)-7 and-8 modulatory activities of dimeric imidazoquinolines. J. Med. Chem. 55, $1106-1116$

(149) Wille-Reece, U., Flynn, B. J., Loré, K., Koup, R. A., Kedl, R. M., Mattapallil, J. J., Weiss, W. R., Roederer, M., and Seder, R. A. (2005) HIV Gag protein conjugated to a Toll-like receptor $7 / 8$ agonist improves the magnitude and quality of Th1 and CD8+ T cell responses in nonhuman primates. Proc. Natl. Acad. Sci. U. S. A. 102, 15190-15194.

(150) Feng, Y., Forsell, M. N. E., Flynn, B., Adams, W., Loré, K., Seder, R., Wyatt, R. T., and Karlsson Hedestam, G. B. (2013) Chemical crosslinking of HIV-1 Env for direct TLR7/8 ligand conjugation compromises recognition of conserved antigenic determinants. Virology 446, 56-65.

(151) Kastenmüller, K., Wille-Reece, U., Lindsay, R. W. B., Trager, L. R., Darrah, P. A., Flynn, B. J., Becker, M. R., Udey, M. C., Clausen, B. E., Igyarto, B. Z., Kaplan, D. H., Kastenmüller, W., Germain, R. N., and Seder, R. A. (2011) Protective T cell immunity in mice following protein-TLR7/8 
agonist-conjugate immunization requires aggregation, type I IFN, and multiple DC subsets. J. Clin. Invest. 121, 1782-1796.

(152) Holbrook, B. C., Kim, J. R., Blevins, L. K., Jorgensen, M. J., Kock, N. D., D’Agostino, R. B., Aycock, S. T., Hadimani, M. B., King, S. B., Parks, G. D., and Alexander-Miller, M. A. (2016) A Novel R848Conjugated Inactivated Influenza Virus Vaccine Is Efficacious and Safe in a Neonate Nonhuman Primate Model. J. Immunol. 197, 555 LP-564.

(153) Holbrook, B. C., D’Agostino, R. B., Tyler Aycock, S., Jorgensen, M. J., Hadimani, M. B., Bruce King, S., and Alexander-Miller, M. A. (2017) Adjuvanting an inactivated influenza vaccine with conjugated R848 improves the level of antibody present at 6 months in a nonhuman primate neonate model. Vaccine 35, 6137-6142.

(154) Holbrook, B. C., Aycock, S. T., Machiele, E., Clemens, E., Gries, D., Jorgensen, M. J., Hadimani, M. B., King, S. B., and Alexander-Miller, M. A. (2017) An R848 adjuvanted influenza vaccine promotes early activation of B cells in the draining lymph nodes of non-human primate neonates. Immunology, in press.

(155) Fujita, Y., Hirai, K., Nishida, K., and Taguchi, H. (2016) 6-(4Amino-2-butyl-imidazoquinolyl)-norleucine: Toll-like receptor 7 and 8 agonist amino acid for self-adjuvanting peptide vaccine. Amino Acids 48 1319-1329.

(156) Bode, C., Zhao, G., Steinhagen, F., Kinjo, T., and Klinman, D. M. (2011) CpG DNA as a vaccine adjuvant. Expert Rev. Vaccines 10, 499-511.

(157) Kreutz, M., Giquel, B., Hu, Q., Abuknesha, R., Uematsu, S., Akira, S., Nestle, F. O., and Diebold, S. S. (2012) Antibody-antigen-adjuvant conjugates enable co-delivery of antigen and adjuvant to dendritic cells in cis but only have partial targeting specificity. PLoS One 7, e40208.

(158) Lee, I., Kwon, H., An, S., Kim, D., Kim, S., Yu, M. K., Lee, J., Lee, T., Im, S., and Jon, S. (2012) Imageable Antigen-Presenting Gold Nanoparticle Vaccines for Effective Cancer Immunotherapy In Vivo. Angew. Chemie Int. Ed. 51, 8800-8805.

(159) Tighe, H., Takabayashi, K., Schwartz, D., Marsden, R., Beck, L., Corbeil, J., Richman, D. D., Eiden Jr., J. J., Spiegelberg, H. L., and Raz, E. (2000) Conjugation of protein to immunostimulatory DNA results in a rapid, long-lasting and potent induction of cell-mediated and humoral immunity. Eur. J. Immunol. 30, 1939-1947.

(160) Kastenmüller, W., Kastenmüller, K., Kurts, C., and Seder, R. A. (2014) Dendritic cell-targeted vaccines - hope or hype? Nat. Rev. Immunol. 14, 705-711.

(161) Yu, D., Zhao, Q., Kandimalla, E. R., and Agrawal, S. (2000) Accessible 5'-end of CpG-containing phosphorothioate oligodeoxynucleotides is essential for immunostimulatory activity. Bioorg. Med. Chem. Lett. 10, 2585-2588.

(162) Kandimalla, E. R., Bhagat, L., Yu, D., Cong, Y., Tang, J., and Agrawal, S. (2002) Conjugation of ligands at the 5'-end of CpG DNA affects immunostimulatory activity. Bioconjug. Chem. 13, 966-974.

(163) Putta, M. R., Zhu, F.-G., Wang, D., Bhagat, L., Dai, M. Kandimalla, E. R., and Agrawal, S. (2010) Peptide Conjugation at the 5' End of Oligodeoxynucleotides Abrogates Toll-Like Receptor 9-Mediated Immune Stimulatory Activity. Bioconjug. Chem. 21, 39-45.

(164) Cai, X., Dong, C., Dong, H., Wang, G., Pauletti, G. M., Pan, X., Wen, H., Mehl, I., Li, Y., and Shi, D. (2012) Effective Gene Delivery Using Stimulus-Responsive Catiomer Designed with Redox-Sensitive Disulfide and Acid-Labile Imine Linkers. Biomacromolecules 13, 1024-1034.

(165) Kramer, K., Young, S. L., and Walker, G. F. (2017) Comparative Study of 5'- and 3'-Linked CpG-Antigen Conjugates for the Induction of Cellular Immune Responses. ACS Omega 2, 227-235.

(166) Kaiser, A., Gaidzik, N., Becker, T., Menge, C., Groh, K., Cai, H., Li, Y.-M., Gerlitzki, B., Schmitt, E., and Kunz, H. (2010) Fully Synthetic Vaccines Consisting of Tumor-Associated MUC1 Glycopeptides and a Lipopeptide Ligand of the Toll-like Receptor 2. Angew. Chemie Int. Ed. 49, 3688-3692.

(167) Cai, H., Sun, Z.-Y., Chen, M.-S., Zhao, Y.-F., Kunz, H., and Li, Y.-M. (2014) Synthetic Multivalent Glycopeptide-Lipopeptide Antitumor Vaccines: Impact of the Cluster Effect on the Killing of Tumor Cells. Angew. Chemie Int. Ed. 53, 1699-1703.

(168) Chan, A., Hussein, W. M., Ghaffar, K. A., Marasini, N., Mostafa, A., Eskandari, S., Batzloff, M. R., Good, M. F., Skwarczynski, M., and Toth, I. (2016) Structure-activity relationship of lipid core peptide-based Group A Streptococcus vaccine candidates. Bioorg. Med. Chem. 24, 30953101.

(169) Abdel-Aal, A.-B. M., El-Naggar, D., Zaman, M., Batzloff, M., and Toth, I. (2012) Design of Fully Synthetic, Self-Adjuvanting Vaccine Incorporating the Tumor-Associated Carbohydrate Tn Antigen and Lipoamino Acid-Based Toll-like Receptor 2 Ligand. J. Med. Chem. 55 ,
6968-6974.

(170) Zaman, M., Abdel-Aal, A.-B. M., Fujita, Y., Phillipps, K. S. M., Batzloff, M. R., Good, M. F., and Toth, I. (2012) Immunological Evaluation of Lipopeptide Group A Streptococcus (GAS) Vaccine: Structure-Activity Relationship. PLoS One 7, e30146.

(171) Wang, Q., Xue, J., and Guo, Z. (2009) Synthesis of a monophosphoryl lipid A derivative and its conjugation to a modified form of a tumor-associated carbohydrate antigen GM3. Chem. Commun. 55365537.

(172) Tang, S., Wang, Q., and Guo, Z. (2010) Synthesis of a Monophosphoryl Derivative of Escherichia coli Lipid A and Its Efficient Coupling to a Tumor-Associated Carbohydrate Antigen. Chem. - A Eur. J. 16, 1319-1325.

(173) Laiño, J., Wangorsch, A., Blanco, F., Wolfheimer, S., Krause, M., Flaczyk, A., Möller, T.-M., Tsai, M., Galli, S., Vieths, S., Toda, M., Scheurer, S., and Schülke, S. (2017) Targeting of Immune Cells by Dual TLR2/7 Ligands Suppresses Features of Allergic Th2 Immune Responses in Mice. J. Immunol. Res. 2017, 7983217.

(174) Sekiya, T., Yamagishi, J., Gray, J. H. V, Whitney, P. G., Martinelli, A., Zeng, W., Wong, C. Y., Sugimoto, C., Jackson, D. C., and Chua, B. Y. (2017) PEGylation of a TLR2-agonist-based vaccine delivery system improves antigen trafficking and the magnitude of ensuing antibody and CD8+ T cell responses. Biomaterials 137, 61-72.

(175) Pavot, V., Rochereau, N., Rességuier, J., Gutjahr, A., Genin, C. Tiraby, G., Perouzel, E., Lioux, T., Vernejoul, F., Verrier, B., and Paul, S. (2014) Cutting Edge: New Chimeric NOD2/TLR2 Adjuvant Drastically Increases Vaccine Immunogenicity. J. Immunol. 193, 5781-5785.

(176) Rice, T. A., Brenner, T. A., Percopo, C. M., Ma, M., Keicher, J. D., Domachowske, J. B., and Rosenberg, H. F. (2016) Signaling via pattern recognition receptors NOD2 and TLR2 contributes to immunomodulatory control of lethal pneumovirus infection. Antiviral Res. 132, 131-140.

(177) Yeung, H., Lee, D. J., Williams, G. M., Harris, P. W. R., Dunbar, R. P., and Brimble, M. A. (2012) A Method for the Generation of Pam2CysBased Lipopeptide Mimics via CuAAC Click Chemistry. Synlett 23, 1617 1620.

(178) Akazawa, T., Ohashi, T., Nakajima, H., Nishizawa, Y., Kodama, K., Sugiura, K., Inaba, T., and Inoue, N. (2014) Development of a dendritic cell-targeting lipopeptide as an immunoadjuvant that inhibits tumor growth without inducing local inflammation. Int. J. Cancer 135, 2847-2856.

(179) Gao, D., Diao, Y., Li, W., Gao, N., Liu, Y., Wang, Z., Jiang, W., and Jin, G. (2015) Toll-Like Receptor 7 Inactive Ligands Enhanced Cytokine Induction by Conjugation to Weak Antigens. ChemMedChem 10, 977-980.

(180) Tighe, H., Takabayashi, K., Schwartz, D., Van Nest, G., Tuck, S., Eiden, J. J., Kagey-Sobotka, A., Creticos, P. S., Lichtenstein, L. M. Spiegelberg, H. L., and Raz, E. (2000) Conjugation of immunostimulatory DNA to the short ragweed allergen Amb a 1 enhances its immunogenicity and reduces its allergenicity. J. Allergy Clin. Immunol. 106, 124-134.

(181) Saneyoshi, H., Yamamoto, Y., Kondo, K., Hiyoshi, Y., and Ono, A. (2017) Conjugatable and Bioreduction Cleavable Linker for the 5'Functionalization of Oligonucleotides. J. Org. Chem. 82, 1796-1802. 
Authors are required to submit a graphic entry for the Table of Contents (TOC) that, in conjunction with the manuscript title, should give the reader a representative idea of one of the following: A key structure, reaction, equation, concept, or theorem, etc., that is discussed in the manuscript. Consult the journal's Instructions for Authors for TOC graphic specifications.

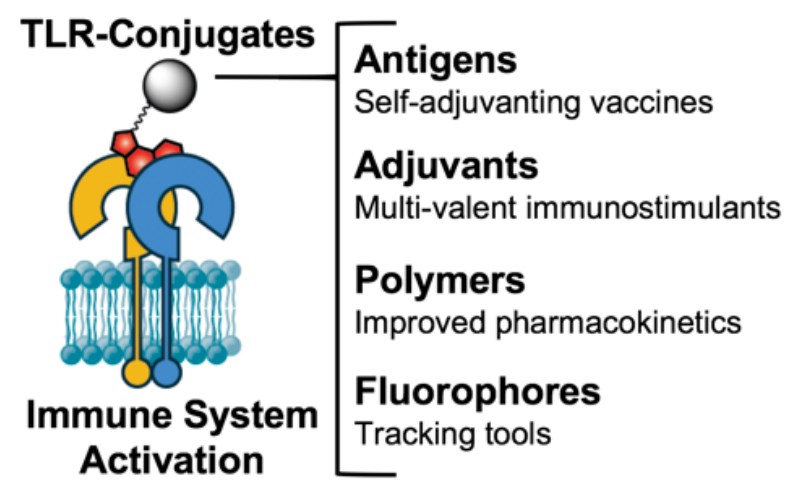

